FELIPE ROCHA VELLOSO DE ALMEIDA PEDROSO

Modelling and Methodology Applied to Evaluate Multi-infeed Performance of HVDC Transmission Systems

São Paulo 
FELIPE ROCHA VELLOSO DE ALMEIDA PEDROSO

\section{Modelling and Methodology Applied to Evaluate Multi-infeed Performance of HVDC Transmission Systems}

Dissertation presented to the Escola

Politécnica da USP for obtainment of the Master Science degree

Concentration area: Power Systems

Supervisor: Prof. Dr. Silvio Giuseppe Di Santo

Co-Supervisor: Prof. Dr. José Antonio Jardini

São Paulo 


\section{Aknowledgements}

I thank my brothers Rafael and Rodrigo, my parents Sérgio and Alice, my grandparents Lóide, Sérgio and Maria Alba and all the others who have always been very present in my life and helped me to find the way here.

I thank Professors Silvio Giuseppe and José Jardini for always being very helpful and always helping me to go one step further in the right direction.

I thank my friends for being by my side in the moments of fun, as in the moments of sadness.

Felipe Pedroso 
Catalogação-na-publicação

\section{Pedroso, Felipe}

Modelling and Methodology Applied to Evaluate Multi-infeed

Performance of HVDC Transmission Systems / F. Pedroso -- Săo Paulo, 2017.

$65 \mathrm{p}$.

Dissertação (Mestrado) - Escola Politécnica da Universidade de São Paulo. Departamento de Engenharia de Energia e Automação Elétricas.

1.HVDC 2.Multi-infeed 3.Falha de comutação 4.LCC 5.Métodos mitigatórios I.Universidade de São Paulo. Escola Politécnica. Departamento de Engenharia de Energia e Automaçăo Elétricas II.t. 


\begin{abstract}
The Brazilian transmission system covers a large area, with a high concentration of consumer centres in the Southeast region and abundant hydro generation in the North. To connect these regions, some of the transmission lines might reach $2500 \mathrm{~km}$ length, creating a challenging situation.
\end{abstract}

In this context, system planners have been defining the use of HVDC systems as the most feasible choice of transmission investment. It is so, recognized that the connections of power plants in the Northern region to the load centres in the Southeast will require a significant number of bipoles and, until the present moment, all the operational and planned HVDC lines are based on the converter technology known as LCC (Line Commutated Converter) and consequently subject to commutation failure.

Currently, the Brazilian system has four LCC bipoles, with two other bipoles under construction. Although the Southeast grid is strong, the connection of two additional bipoles is a concern as the interaction between these inverters may cause strong effects on one another, a phenomenon known as multi-infeed interaction. In such a situation, the assessment of the system operation, possible outages and possible mitigation methods are of paramount importance.

This document presents a different methodology for the analysis of the multi-infeed system mentioned and focuses on its validation by analysing operation under normal conditions and with the implementation of established mitigation methods.

The investigation was carried out with EMT, power flow, short-circuit and electromechanical softwares in a very large AC system composed by 100 buses on EMT and full Brazilian system on the rest. The effects of faults were analysed and the areas containing the buses where a fault leads to multiple commutation failures were identified.

\title{
KEYWORDS
}

HVDC, multi-infeed, commutation failure, LCC, extinction angle, synchronous condenser, Statcom 


\section{RESUMO}

O sistema de brasileiro de transmissão abrange uma área ampla, com uma alta concentração de consumo na região Sudeste e abundante geração hidrelétrica no Norte. Para conectar essas regiões, algumas das linhas de transmissão podem alcançar comprimentos de $2500 \mathrm{~km}$, criando uma situação desafiadora.

Neste contexto, os planejadores de sistemas têm definido o uso de sistemas HVDC como a escolha mais viável de investimento em transmissão. É então reconhecido que as conexões de usinas na região Norte aos centros consumidores no Sudeste exigirão um número significativo de bipolos e, até o momento presente, todas as linhas HVDC operacionais e planejadas são baseadas na tecnologia de conversão conhecida como LCC (Line Commutated Converter) e consequentemente sujeito a falha de comutação.

Atualmente, o sistema brasileiro tem quatro bipolos LCC, com outros dois bipolos em construção. Embora a rede do Sudeste seja considerada forte, a conexão de dois bipolos adicionais é uma preocupação, pois a interação entre esses inversores pode causar efeitos danosos uns sobre os outros, um fenômeno conhecido como interação multi-infeed. Em tal situação, a avaliação da operação do sistema, possíveis interrupções e possíveis métodos de mitigação são de suma importância.

Este documento apresenta uma metodologia diferente para a análise do sistema multi-infeed mencionado e foca em sua validação, analisando a operação em condições normais e com a implementação de métodos de mitigação conhecidos.

A investigação foi realizada com softwares EMT, de curto circuito, fluxo de potência e estabilidade eletromecância em um sistema CA muito grande composto por 100 barras em EMT e sistema brasileiro completo no resto. Os efeitos das falhas foram analisados e as áreas que contêm as barras onde uma falha leva a múltiplas falhas de comutação foram identificadas.

\section{PALAVRAS CHAVE}

HVDC, multi-infeed, falha de comutação, LCC, ângulo de extinção, compensador síncrono, Statcom. 


\section{LIST OF FIGURES}

Figure 1 - Graetz bridge.

Figure 2 - Map of lines and substations - Southeast.

Figure 3 - Break-even distance of AC versus DC transmission. 20

Figure 4 - Brazilian HVDC grid by 2020 21

Figure 5 - Planned future HVDC projects by 2020 in China.

Figure 6 - Voltage drop during single-phase fault 28

Figure 7 - Flowchart of the methodology 30

Figure 8 - Critical areas on maximum short circuit scenario $\left(18^{\circ}\right)$ 36

Figure 9 - Critical areas on minimum short circuit scenario $\left(18^{\circ}\right)$ 36

Figure 10 - Critical areas on maximum short circuit scenario $\left(\gamma=24^{\circ}\right)$ 38

Figure 11 - Critical areas on minimum short circuit scenario respectively $\left(\gamma=24^{\circ}\right)$ 38

Figure 12 - Critical areas on maximum short circuit scenario (Synchronous/Statcom) 40

Figure 13 - Critical areas on minimum short circuit scenario (Synchronous/Statcom). 41

Figure 14 - Power on Belo Monte bipole 1. 44

Figure 15 - Voltages on Belo Monte inverter system 2 pole 1 45

Figure 16 - Estreito AC bus voltage (Belo Monte system 2)

Figure 17 - Alpha on Belo Monte rectifier system 1 pole 1 47

Figure 18 - Alpha on Belo Monte Inverter system 2 pole 1 .48

Figure 19 - Power on the machines after solid short-circuit at Araraquara 2 AC bus 49 
Figure 20 - Commutation of valves 1 and 3.

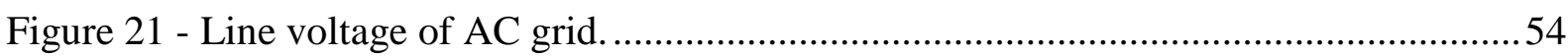

Figure 22 - Current during a cycle focusing on the commutation process............................55

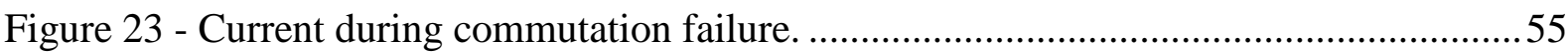

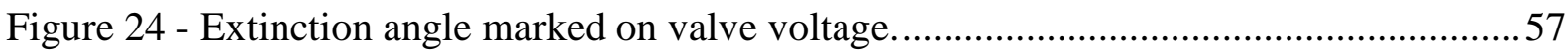

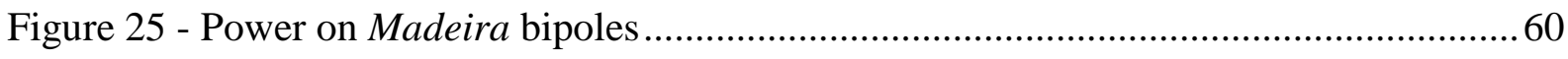

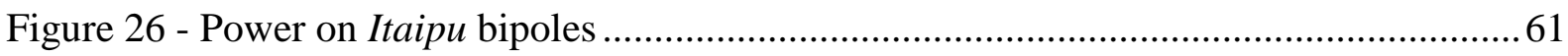

Figure 27 - Power on Belo Monte bipole 1 (Same figure presented in section 5.3.2 Power

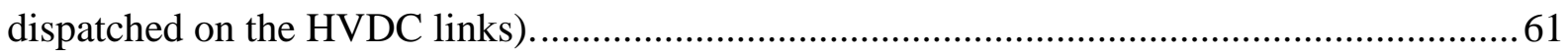

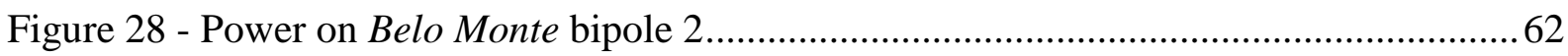




\section{LIST OF TABLES}

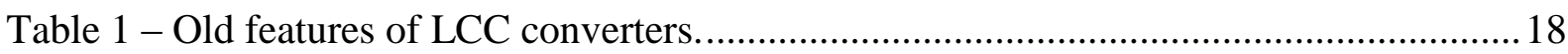

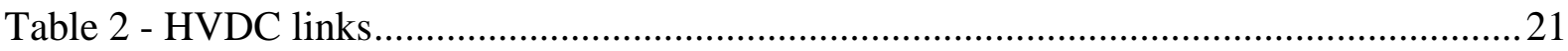

Table 3 - MIIF under different season and load conditions. a) Light load - North dry; b) Average load - Norht dry; c)Heavy load - North dry; d) Light load - Norht wet; e) Average load - North wet; f) Heavy load - North wet .................................................................... 32

Table 4 - MIESCR calculated with maximum and minimum short circuit values. a) Maximum short-circuit scenario; b) Minimum short-circuit scenario

Table 5 - Events simulated for short-circuit mapping 34

Table 6 - Voltage drop limits of commutation failure (\%) 35

Table 7 - Initial limits for voltage drop before commutation failure (\%)

Table 8 - Voltage drop limits for different situations of failure (\%) 39

Table 9 - Power Plants represented as Machines in the PSCAD 42

Table 10 - Maximum Short-Circuit values for the year 2020 - ANAFAS EPE 2020 58

Table 11 - Minimum Short-Circuit values for the year 2020 - ANAFAS EPE 2020. 58

Table 12 - Nominal Power of the HVDC Systems planned to be operational by the year 2020 .

Table 13 - HVDC Filters Injected Reactive Power for the various Load Flow Situations.

Table 14 - ESCR Calculated with maximum and minimum short circuit values. a) Maximum short-circuit scenario; b) Minimum short-circuit scenario 59

Table 15 - Lines included for the connection of the synchronous machines 63 


\section{Summary}

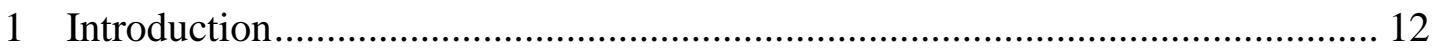

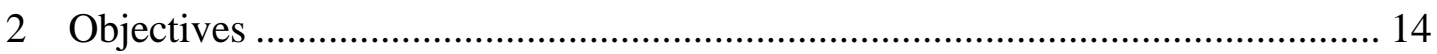

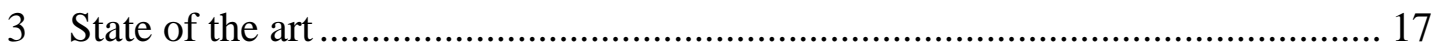

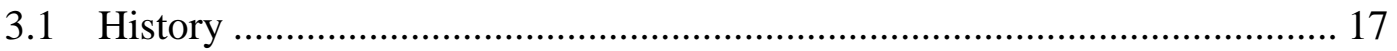

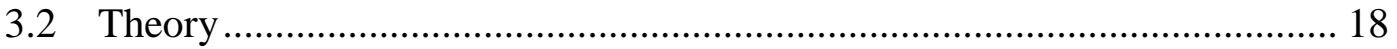

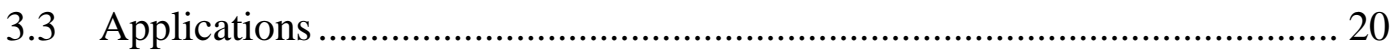

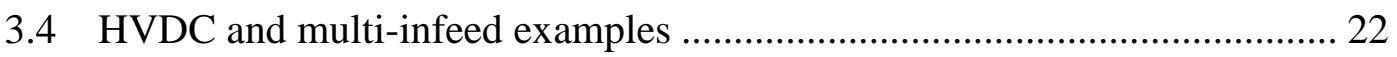

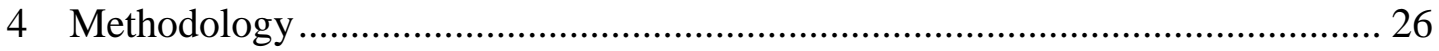

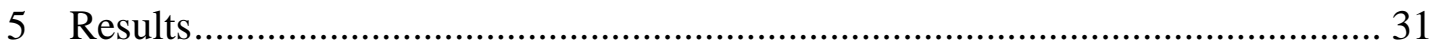

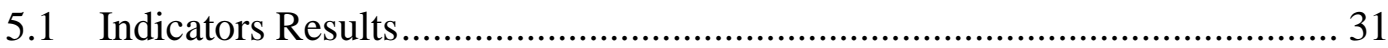

5.1.1 STABILITY AND SHORT-CIRCUIT STUDIES …...................................... 31

5.1.2 Multi-infeed Interaction Factor - MIIF ........................................................ 31

5.1.3 Multi-infeed Equivalent Short Circuit Ratio - MIESCR ................................33

5.2 Mapping of critical short-circuits areas .................................................... 34

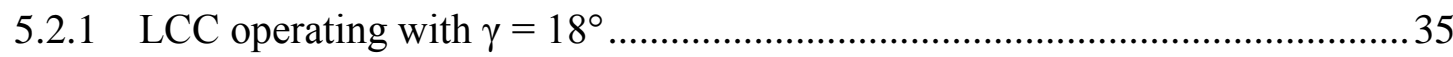

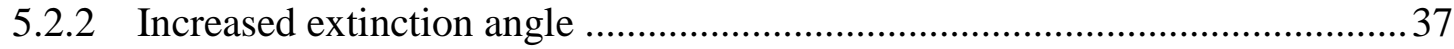

5.2.3 Use of synchronous condensers or Statcoms on inverters buses .....................40

5.3 DYNAMIC PERFORMANCE: FAULT APPLICATION .......................... 41

5.3.1 Performance Comparison: Machines and Equivalents - Three-Phase ShortCircuit 41

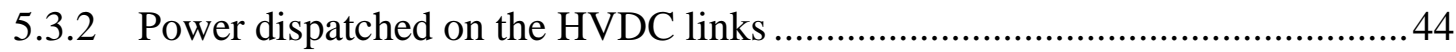

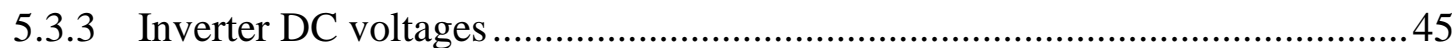




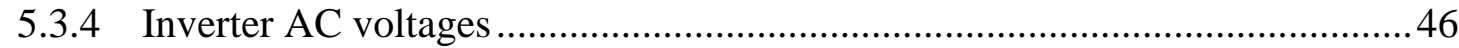

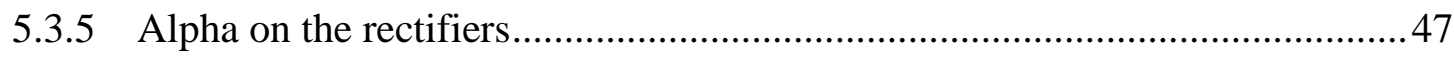

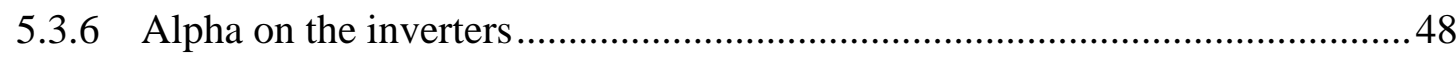

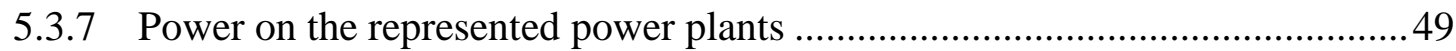

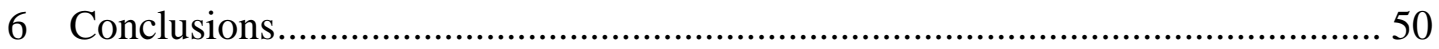

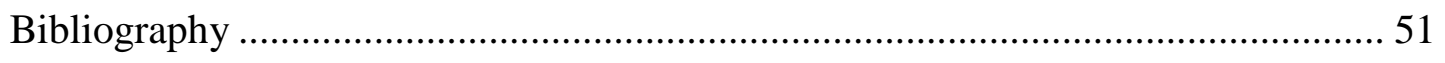

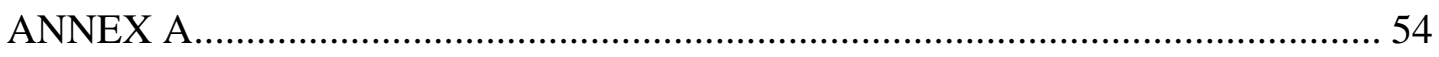

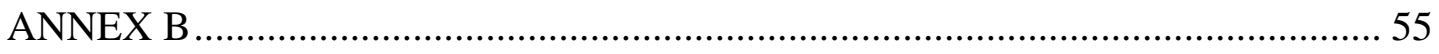

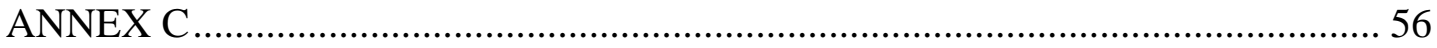

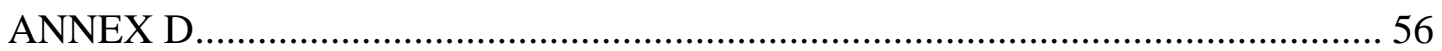

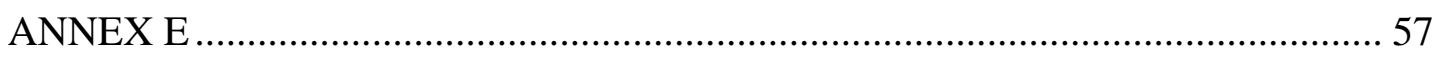

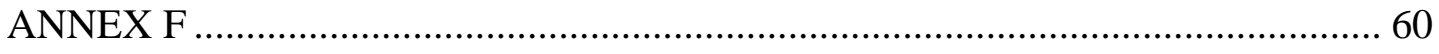

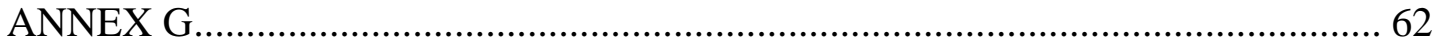




\section{INTRODUCTION}

The crescent demand for electric power has led to a great development of bulk power transmission technologies, transmitting power generated from many kilometres away to large consumer centres.

The Southeast region of Brazil is the most developed one and concentrates the highest number of industries, population and economic growth, resulting in a tremendous energy consumption compared to the rest of the country. The power generation in the region, however, is close to saturation and the alternatives are everyday more dependent on the power plants remotely located in the country.

The expansion of the Southeast region has become, therefore, a critical planning issue for political, economic and social interest and so naturally, new projects of power generation are being held, mainly in the Amazon Basin.

The technical potential for the use of hydroelectric power in Brazil is amongst the five largest in the world, with estimates of around $260 \mathrm{GW}$, from which $40.5 \%$ is located in the Amazon Basin. The North Region, in particular, has great potential yet to be explored. [1]

Some of the hydro power plants in the bidding process or operating in the Amazon Basin are in the list of the ten largest in Brazil: [1]

- Belo Monte (which will have installed capacity of 11233 megawatts);

- São Luiz do Tapajós (8381 MW);

- $\operatorname{Jirau}(3750 \mathrm{MW})$;

- Santo Antônio (3150MW).

Amongst the largest power plants in operation in Brazil are Itaipu (14000 MW, or $16.4 \%$ of the energy consumed in Brazil), Tucuruí (8730 MW), Ilha Solteira (3444 MW), Xingó (3162 MW) and Paulo Afonso IV (2462 MW). [1]

The most feasible choice of power transmission connecting the above mentioned hydro potential to the consumer centres is the use of HVDC links. Lines of thousands of kilometres are already operating or being assembled to provide the necessary infrastructure for the maintenance of the Southeast economic expansion. 
The connection of these remote power plants and the consequences of the use of HVDC technologies are the target of this research, which is divided into the following parts:

Chapter two addresses the objectives of this research, and discuss the studies developed by meanings of simulations, which was ran under the software ANAREDE, ANAFAS, ANATEM, and PSCAD. Also, it explains the features of each program. Besides, this chapter exposes the Southeast Brazilian subsystem overall peculiarities and set the limits of this study.

Chapter three is the State of Art and discuss about the operation of LCC, defining its operation by means of descriptions and graphs and mentioning worldwide known HVDC projects. Furthermore, it discusses about some peculiarities and issues faced by LCC during operation and multi-infeed interaction situations.

Chapter four describes the proposed methodology to present an easy understanding and evaluation of the multi-infeed interaction in the Southeast region of Brazil.

Chapter five has the results obtained by using the methodology described and how powerful this methodology can be when evaluating macro regions and correspondent influence of diverse results collection' locals.

Chapters six and seven show the results obtained by the proposed methodology.

Chapter eight presents the conclusions regarding the results obtained and the comparison of results based on the methodology. 


\section{OBJECTIVES}

This document is a final piece of a series of multi-infeed studies conducted throughout the Brazilian system, focusing in the Northern and mainly Southeast regions of Brazil.

The studies were meant to assess the multi-infeed phenomena occurrence and its effects, specially the occurrence of consequential commutation failure (also known as concurrent commutation failure), due to active and reactive power exchange amongst converters, whereas the converters operating as single-infeed systems would not generate concerns of commutation failure incurring in outages.

Commutation is the process of transfer of current from one valve to the subsequent one [2] [3]. The sequence of conduction can be seen in Figure 1 from valve 1 to 6 .

Figure 1 - Graetz bridge.

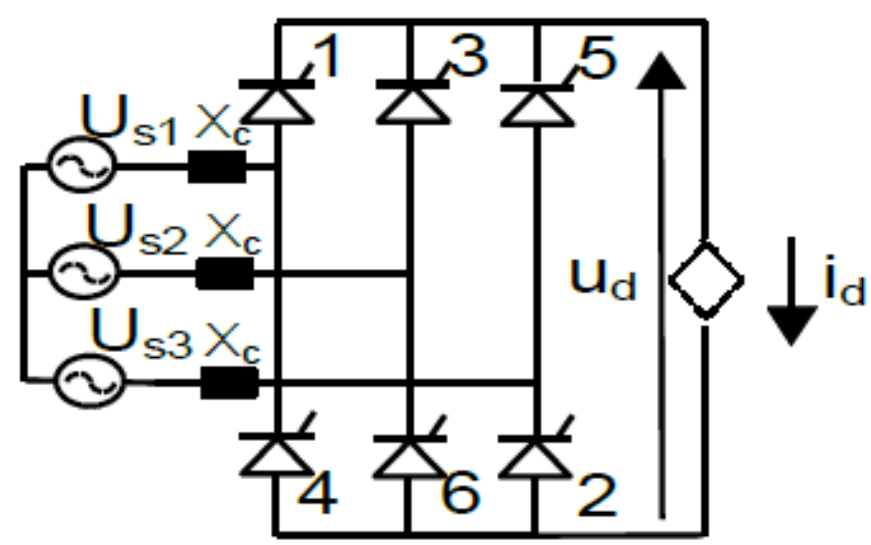

Source: Adapted from [4]

When out of the commutation period, only two valves conduct at the same time in normal situations, but during the process of commutation three valves conduct at a time, two in the upper or lower row and one in the opposite row. The two valves who conduct in the same row create a short circuit between two of the phases of the AC side. ANNEX A illustrates this situation.

This process is natural and essential for the LCC correct operation. However, failures in this process may occur. Changes of parameters regarding: 
- Voltage harmonic distortions;

- Transient overvoltage;

- Phase shifts incurring in power exchange alterations

are considered main causes of commutation failure.

A situation of commutation failure happens usually when some of the above-mentioned factors arise and it is evidenced by the failure in current transfer between two thyristors. See ANNEX B.

Since a consequential commutation failure may lead to system collapse, its effects and outcomes will be hereafter exhaustively evaluated, in order to create a new methodology deeply elaborated in the details.

In order to address, and then evaluate multi-infeed phenomena, it is necessary to follow a sequence of steps. Firstly to understand the magnitude of the phenomena in the studied network and secondly to determine the necessary detailing of the system and the simulations to be performed.

The programs used in this study are described next:

- ANAREDE - Power flow analysis;

- $\quad$ ANAFAS - Short circuit analysis;

- ANATEM - Electromechanical stability analysis;

- PSCAD - Electromagnetic transients analysis.

To develop the analysis of the extensions of the phenomena, the first studies were based on simulations of the Cepel (Electrical Energy Research Centre) software ANAREDE, ANAFAS and ANATEM. The models used were made publically available by EPE (Brazilian Planning Agency) in [5], targeting the year 2020.

All these phenomena are poorly represented in typical stability programs such as ANATEM and, therefore, moving to a more sophisticated modelling and using other kind of tool is essential. 
Thus, it is necessary to bring these simulations to an EMT (Electro Magnetic Transients) software, capable of modelling nonlinearities that are not present in the ANATEM software. The models used in this part of the study were also made publically available by EPE in [5].

The EMT analysis will be the most valuable piece of the work under assessment, since commutation failures happen mostly transitorily. The final intention is to map as many situations as possible and so create a diagnosis about the operation of the multi-infeed network that will be present in Brazil by 2020 .

The multi-infeed network is restricted to the Southeast region, which is represented by Figure 2.

Figure 2 - Map of lines and substations - Southeast.

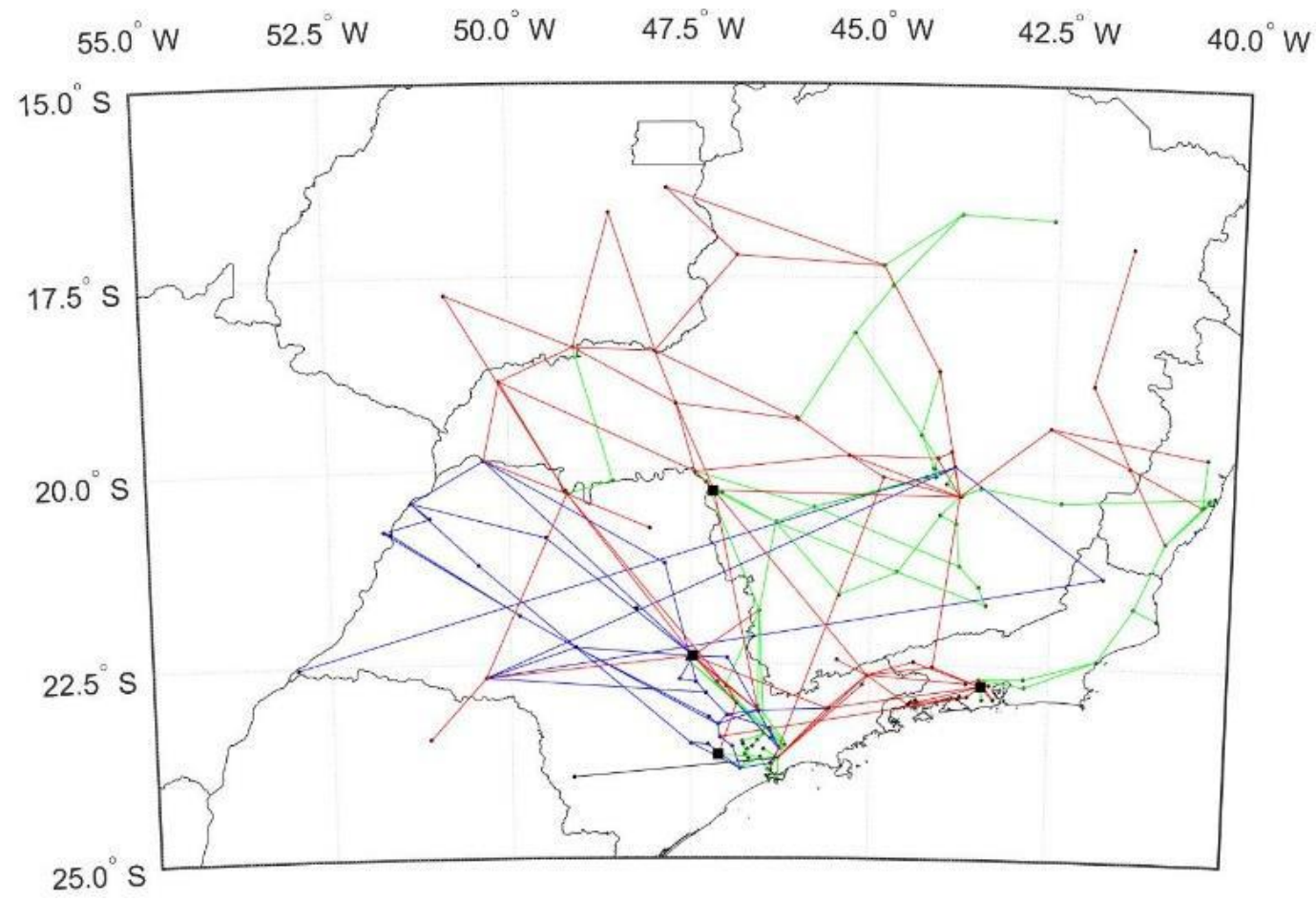

Source: Author.

Where:

- Square black points - Inverters terminals;

- Green lines - $345 \mathrm{kV}$;

- Blue lines - $440 \mathrm{kV}$;

- Red lines $-500 \mathrm{kV}$. 


\section{STATE OF THE ART}

For better understanding, this chapter is divided into history, theory, applications and examples.

\subsection{History}

From the episode known as the "War of Current" until current days, the most common way to operate transmission lines is with $\mathrm{AC}$ (alternating current) technologies, enshrined by the ease voltage increase through transformers, which minimize transmission losses [6].

The historical application of HVDC (High Voltage Direct Current) systems occurred in situations where significant technical and economical advantages accrued over comparable HVAC (High Voltage Alternate Current) systems when HVAC technical solutions did not exist. HVDC systems were implemented for:

- Long distance overhead bulk power transmittal;

- Connecting systems of different nominal frequencies;

- Connecting asynchronous systems;

- Cable systems, especially undersea over longer distances.

Such situations were specialized and relatively sparse and consequently the interaction between adjacent HVDC systems was rarely considered.

However, since the 1960s, applications of power electronics in power, generation, distribution and transmission systems have been rapidly developing new technologies and gaining space in the market [3].

The first commercial HVDC transmission connecting the island of Gotland (biggest island in Sweden) to the continent via submarine cable began to operate in 1964.

Reference [2], published in 1971, was one of the first to consolidate technical and economic aspects regarding the operation of HVDC systems. 
To study the peculiarities of the HVDC systems, Cigré (Conseil International des Grands Réseaux Électriques) developed, in 1991, was the first EMT benchmark model of HVDC systems. [7]

Right after the disclosure and propagation of this EMT model, new models have emerged in ATP and SIMULINK/MATLAB programs [7].

\subsection{Theory}

The year of 1955 was remarkable for the evolution of HVDC systems, when a new switching device was created and called thyristor, becoming a cheaper and more compact alternative to mercury valve arcs. Few years later it was already capable of withstanding the conduction of high voltages and currents, required for the use in HVDC applications, its first application was in the Gotland island, already mentioned.

The Gotland HVDC system presented, by the time, some features which are shown in Table 1.

Table 1 - Old features of LCC converters.

\begin{tabular}{l|l}
\hline Converters & Mercury arc valves \\
\hline Filtering & Single tuned immersed in oil \\
\hline Control & Analog - only essential functions \\
\hline
\end{tabular}

Source: [8]

More recent features changes of HVDC systems include: [8]

- Replacing of Mercury valve arcs by thyristors;

- Replacing of oil immersed reactors by air insulated ones;

- The use of series capacitors to help commutation (is under study);

- PWM technology started to be applied specially in Voltage Source Converters $\left(\operatorname{VSC}^{1}\right)$;

\footnotetext{
${ }^{1}$ Although LCC is the most common way of HVDC transmission, the new VSC (Voltage Source Converter) technology has been gaining space in more recent years.
} 
- Valves have decreased in size;

- Filters became double tuned with higher Q factor;

- Digital control with protection functions appeared;

- Operators interface has become minimum;

- Fibre optics now do the communication.

The thyristor valve properties include: [2] [9]

- The need for a positive voltage across terminals for turn on;

- Last statement implies that the converter can only draw an inductive power from the AC network;

- Turn off depends on commutation between valves;

- Voltages required for latest processes are furnished by;

- The voltages required for the turning on and off of the valves have to be supplied by the ac network;

- Shunt compensation of around 50-60\% of active power transmitted is necessary but also creates greater instabilities during disturbances.

Despite the technical aspects mentioned, the main factor of influence for the establishment of HVDC systems is the economic advantage provided by the application of DC lines. Figure 3 shows the break-even distance for the advantageous use of HVDC schemes, which is usually in the range of 500 to $800 \mathrm{~km}$ depending on the location of the project [10].

In recent years, a number of factors (especially economic questions) have contributed to an increasing consideration of HVDC applications. As a result, HVDC systems are being planned in closer proximity and their influence on each other known as multi-infeed interaction, as it affects the overall AC system performance, is a significant planning concern [11]. 
Figure 3 - Break-even distance of AC versus DC transmission.

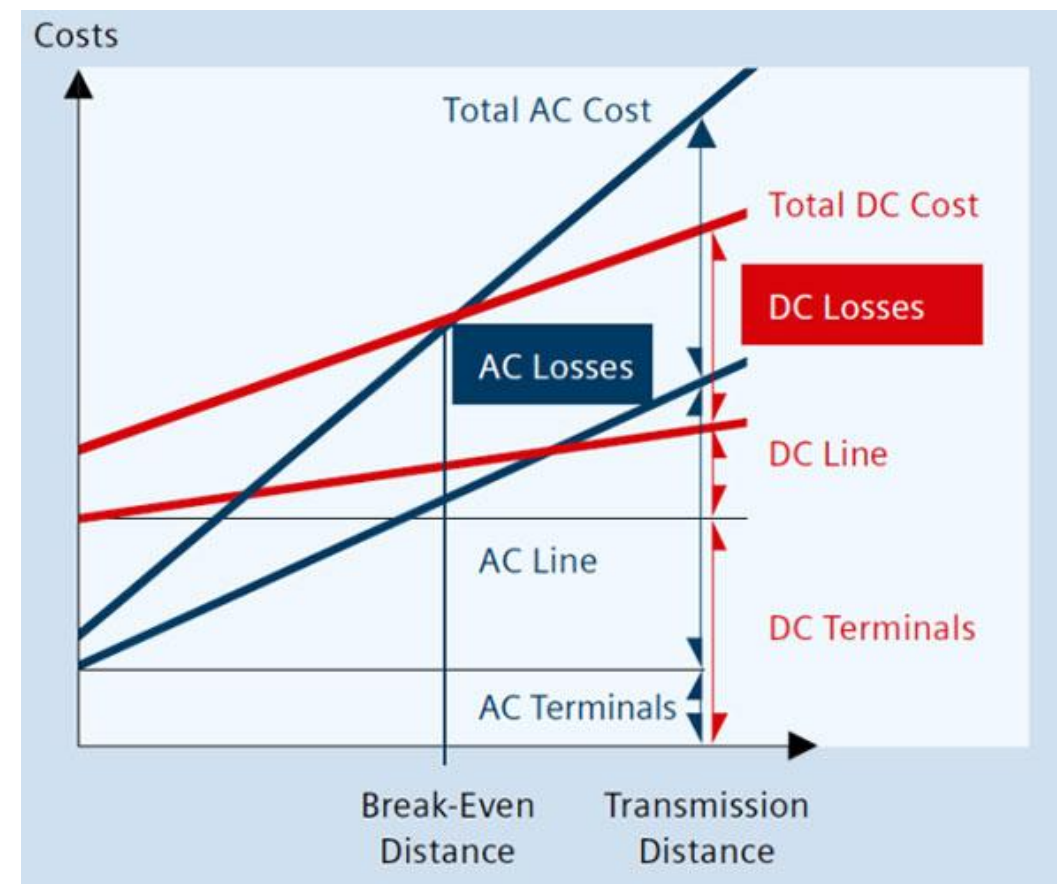

Source: [10]

\subsection{Applications}

In Brazil, direct current transmission is used for point-to-point transmission and the power flow is unidirectional. This type of transmission uses LCC (Line Commutated Converter) but studies about the use of CCC (Capacitor Commutated Converters, which is an LCC system with capacitors placed between the converter bridge and the transformer) are gaining space, such as the study mentioned in [12].

In the upcoming years, new HVDC-LCC bipoles for long distance bulk power transmission are planned for the Brazilian electrical system. Apart from the Brazilian case, situations of remote generation sites (specially the renewable ones) are a worldwide trend [13].

In Brazil, the new bipoles named Belo Monte 1 and Belo Monte 2 are expected to arrive in a close and dense electrical region where two other LCC systems are already operational, namely Itaipu and Madeira. This situation is illustrated Figure 4 and Table 2 
Table 2 - HVDC links

\begin{tabular}{l|l|l|l|l|l|l}
\hline DC Link & Rectifier & Inverter & $\mathrm{MW}$ & $\mathrm{kVdc}$ & $\mathrm{km}$ & $\begin{array}{l}\text { Inverter } \\
\mathrm{kVac}\end{array}$ \\
\hline Itaipu & Foz do Iguacu & Ibiuna (IB) & $2 \times 3150$ & \pm 600 & 800 & 345 \\
\hline Madeira & Porto Velho & Araraquara 2 (AR) & $2 \times 3150$ & \pm 600 & 2500 & 500 \\
\hline Belo Monte 1* & Xingu & Estreito (ES) & 4000 & \pm 800 & 2200 & 500 \\
\hline Belo Monte 2* & Xingu & Terminal Rio (TR) & 4000 & \pm 800 & 2500 & 500 \\
\hline
\end{tabular}

Source: [14]

Figure 4 - Brazilian HVDC grid by 2020

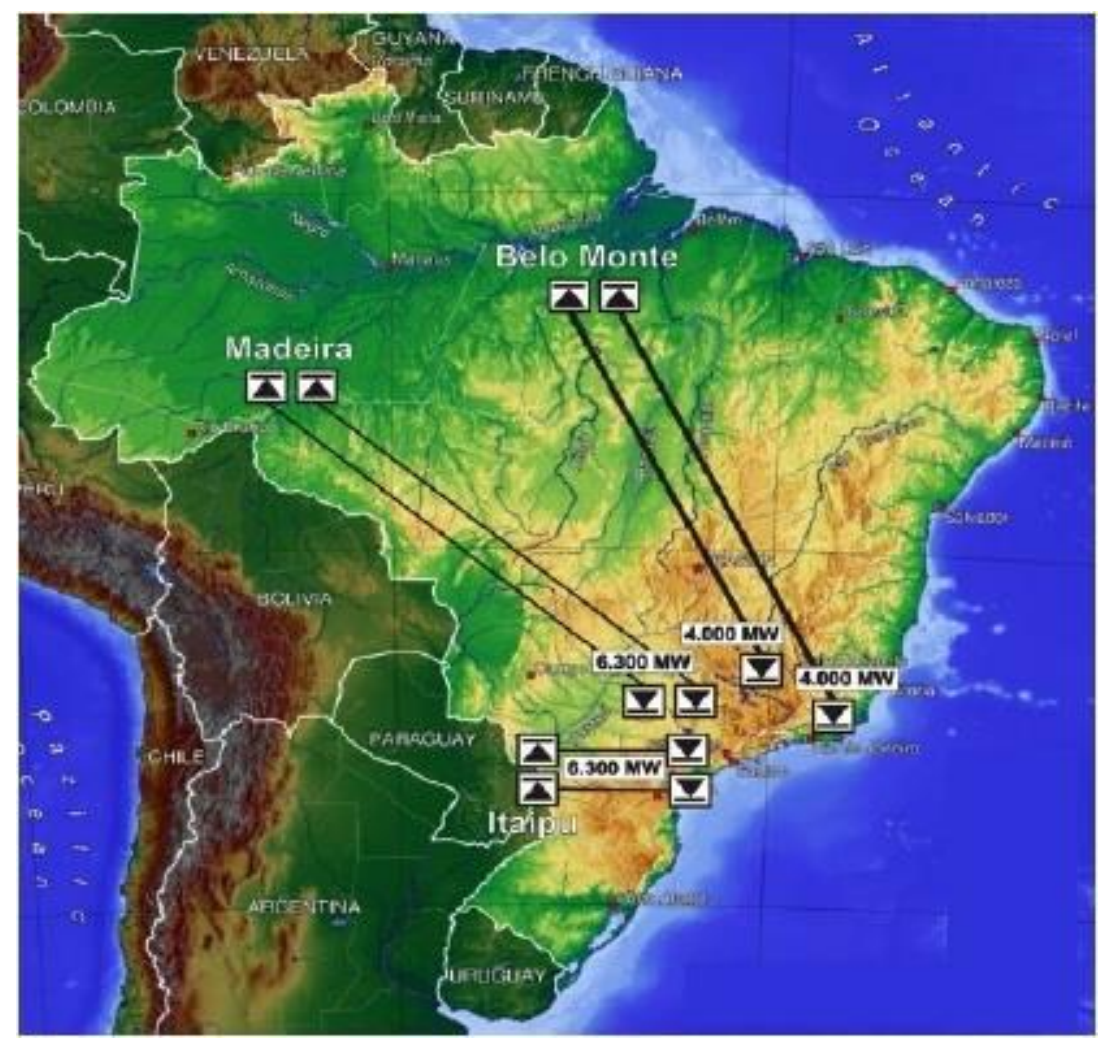

Source: [15]

The new grid configuration raises concerns regarding the interaction between the converters. Effects regarding AC/DC converters interaction as system stability, harmonics propagation and consequential commutation failures need to be extensively studied in order to ensure secure and optimal system operation [11]. 
It is important to notice that technically there is no limit for the number of HVDC links that may co-exist in a relatively congested electrical space. However, as the density of HVDC links increase, the sharing of system short circuit level by all affected inverters may lower to the point where further HVDC development becomes difficult. As HVDC systems increase, the SCR (Short-Circuit Ratio) will be lower and more difficult and complex operational conditions will arise, for instance the need for faster controls [9] [11].

This multi-infeed special kind of network gives rise to a greater interest in studying the performance of such applications, since the interaction amongst the HVDC system may jeopardy the network stability.

Because of the strong interactions amongst converters located in close electrical proximity, the commutation process increases in complexity and start influencing each other.

At this point, special attention is assigned to the consequential commutation process, which is a special troublesome situation. The commutation processes influence each other and the commutation failure in one inverter can outcome in commutation failures in other converters, whilst it would not occur in a single-infeed system.

\subsection{HVDC and multi-infeed examples}

As the emergence of HVDC transmission systems advantages is restricted to a few places in the world, with large dimensions, this sort of situation is encountered mainly in places like:

- Brazil;

- Canada [16];

- China [16] [17];

- India [18] [19] [20];

- Northern Europe [16];

- Southern California [21].

Obs: Some of the references were suggested by [7].

Perhaps the greatest example of multi-infeed network is China. The Chinese have been investing substantial amounts of money in infrastructure used to maintain its economic 
growth, searching for cheaper and environmentally friendly sources of energy. The HVDC projects operational and planned in China are described in Figure 5.

Figure 5 - Planned future HVDC projects by 2020 in China

\section{Planned Future HVDC Projects by 2020 in China}

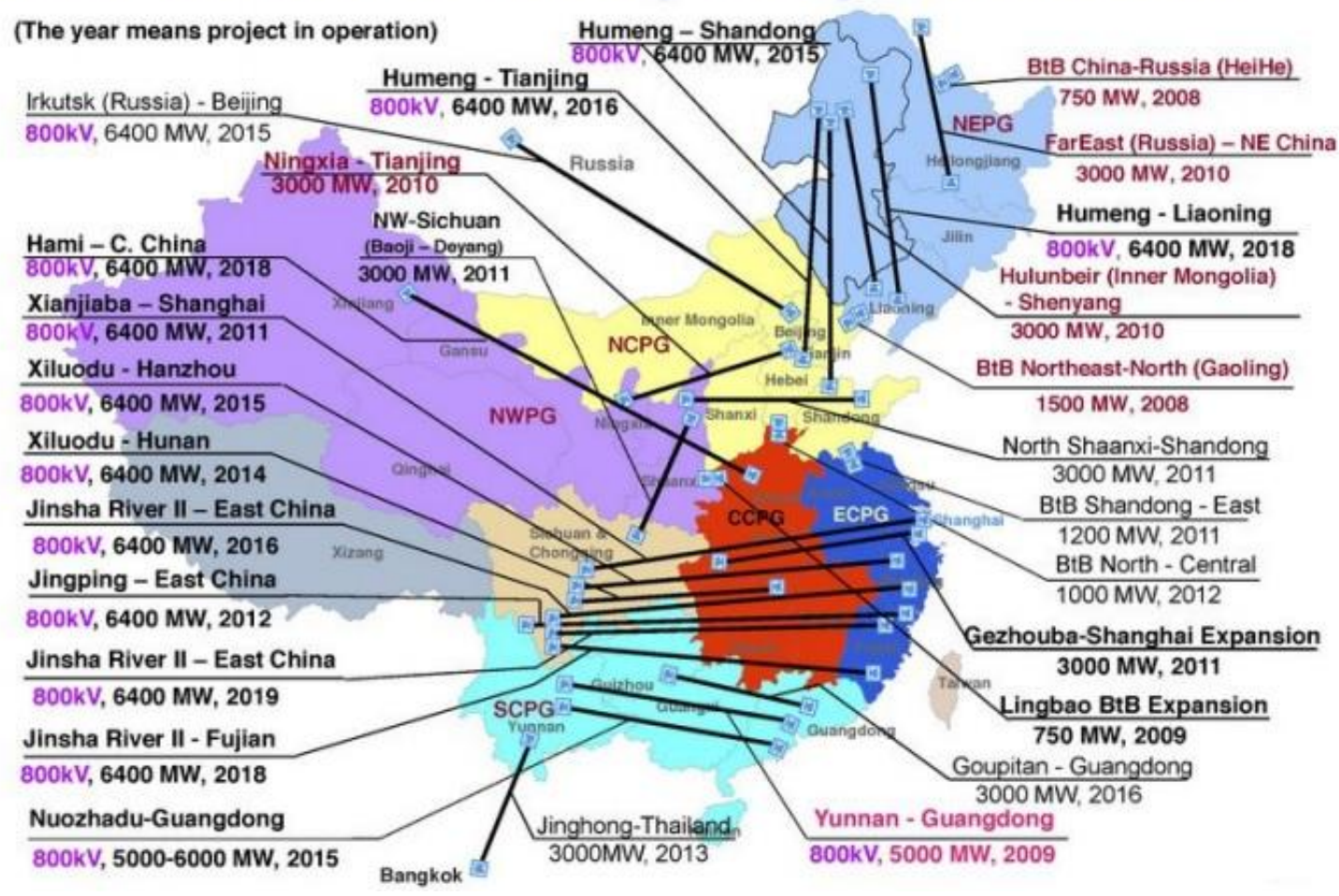

Source: [6]

Multi-infeed phenomena that may arise could be the source of major instabilities in the system, causing consequential commutation failure in all the electrically close inverters and therefore leading the system to a total collapse. In Brazil, for example, a consequential failure in the Itaipu and Madeira systems could suddenly remove $12600 \mathrm{MW}$ of power injected in the system, getting worse as new bipoles, as the Belo Monte bipoles, are inserted. One of the consequences of such event would be a massive load rejection and large transients that could disconnect most of the Southeast region of Brazil [15].

Four technical interaction phenomena are of main interest in a multi-infeed network, composed by overhead cable systems: [11] [16] [22]

- Transient Over Voltage (TOV); 
- Commutation Failure including Fault Recovery (focus of this research);

- Harmonic Interaction;

- Power Voltage Instability and Control Interaction.

The most common misoperation regards to LCC performance, commutation failures of an HVDC transmission system often generate significant disturbances in the operation of an AC system. As mentioned before, the central reasons for commutation failures are: [2]

- Increased direct current (phase shift);

- Low AC voltage;

- Harmonic distortions;

- Late ignition, caused by malfunction of control or components.

Increased DC currents are rare, as the smoothing reactor prevents rapid variations, late ignition due to inadequate control of time ignition is also rare, since the control functions and routines are solidly defined. Therefore, $\mathrm{AC}$ voltage reduction due to faults in the inverter $\mathrm{AC}$ system are the fundamental justification of a commutation failure [2] [16].

The fault location is an acutely crucial factor, the closer it is to an inverter bus, the higher the probability of the voltage interaction to imply in commutation failure in the converter, therefore [16] classifies the faults as:

- Local - Causes commutation failure of the inverter regardless the dynamics introduced by other converters nearby;

- Concurrent (or consequential) - Commutation failure in one or more inverters, which are assigned in part to the dynamics introduced by the converters interaction and in part by the fault itself.

A multi-infeed region may create situations where, due to the sharing of the short-circuit level, the voltage and power interaction of the network induces commutation failure in an electrically near converter, whereas a similar, only more robust, network would not result in concurrent commutation failure [16]. 
Until now it has only been explored the possibility of commutation failure, but the behaviour of the HVDC links and its recovery time back to full power operation governed by the control properties is crucial, since commutation failures will soon or later happen in an HVDC link.

There is a trade-off between commutation failure susceptibility and commutation failure recovery time. In an $\mathrm{AC}$ system, more susceptible to faults and, therefore, commutation failure, the features of control must be finely adjusted, insuring fast operation to correct the problematic power transmission. In the other hand, system that are better planned and reinforced may not need the control act performance to guarantee that commutation failure will not occur, the system will be able to quickly restore the AC voltage and so normal commutation can be restored [16].

Systems with single or multiple DC infeed present well distinguished features that are not yet completely understood and restricted to few countries who usually present continental dimensions.

So far as the use of HVDC links becomes a feasible choice, a problem of first importance is devolved to the ONS (National System Operator) who is putting large efforts on analysing the interaction phenomena and the level of extension met.

Most of the multi-infeed studies address the problem with the use of the methodology described by [16]. The analysis developed here tries to draw a new methodology that should be able to provide a better understanding of the problem.

Based on detailed technical studies and with the aid of concepts explained in this report, this will be the deliberation about the limitations of the addition of HVDC systems in the same electrical network. 


\section{METHODOLOGY}

One of the renowned techniques to quantify the probability of multi-infeed interaction occurrence is described in [16], where some indicators are created and described as to provide a first level indication of the degree of interaction amongst HVDC systems and will be briefly summarized below.

The first indicator mentioned is the MIIF (Multi-Infeed Interaction Factor) which measures the degree of interaction between the voltages of two different buses creating, therefore, the possibility of analysing how a voltage change in a certain bus influences the voltage in another electrically near bus.

The MIIF is calculated by:

$$
M I I F_{e, n}=\frac{\Delta V_{e}}{\Delta V_{n}}
$$

Where:

$\Delta \mathrm{Vn}-$ Small induced voltage at bus $n$;

$\Delta \mathrm{Vn}-$ Observed voltage change at bus $e$.

According to [16]:

- $0.15<$ MIIF represents no relevant interaction;

- $0.15 \leq \mathrm{MIIF} \leq 0.3$ represents some degree of interaction;

- MIIF > 0.3 represents possible concerns concurrent commutation failure.

Still according to [16] the MIIF approach is sufficient when the HVDC systems ending in near electrical regions are of similar capacity.

If links of different capacities are planned to be inserted in electrical near regions, other approaches must be taken into account, for instance the indicator termed MIESCR (MultiInfeed Effective Short Circuit Ratio) which is the multi-infeed definition of the effective short circuit ratio (see ANNEX C). 
This indicator will show whether the AC network is sufficiently strong to embed all HVDC links planned. The MIESCR is defined by [16]:

$$
\operatorname{MIESCR}_{i}=\frac{S C C_{i}-Q f_{i}}{P d c_{i}+\Sigma_{j}\left(M I I F_{j, i} * P d c_{j}\right)}
$$

Where:

SCC - Short Circuit level

Qf - Shunt compensation of inverter bus

Pdc - HVDC link rated power

According to [16] and [23]:

- $\operatorname{MIESCR}<2$ very weak AC system;

- $2 \leq \mathrm{MIESCR} \leq 3$ weak AC system;

- $\quad$ MIESCR > 3 strong AC system;

These indicators are an overview of the problem, which will indicate probabilities of interaction amongst converters. However, they cannot detect which will be the interactions and its magnitudes, which is why this document proposes a complementary new methodology to assess the evaluation of the multi-infeed phenomena that will be tested in the Brazilian system.

Furthermore, multi-infeed phenomena are particularly present in highly meshed networks, which is the case of the Southeast region system. That is another enough reason to propose this methodology and carry out an evaluation of the Southeast subsystem voltage interactions amongst inverter terminals [15].

The proposed methodology uses studies of voltage drop under short circuit conditions, in the EMT model described in the chapter "Objectives", by applying single and three-phase faults on the inverter buses listed in Table 2, through fault reactance [14]. The fault reactance was systematically reduced, until the inverter under study reached commutation failure, thus determining a limit of line voltage drop. The limits were based on the lowest values of fault impedance that will not cause commutation failure. [24]. 
The limits for commutation failure were defined as the percentage voltage drop between the RMS voltage value measured right before the fault and the RMS voltage value measured with the limit fault reactance applied, after steady state of fault was reached, on EMT software. It is important to mention that it was used line voltage for the determination of such limits, since it is the line voltage that is applied to the converters. Figure 6 shows the limiting drop, where the fault starts at $2.2 \mathrm{~s}$.

After determining the voltage drop limits for all four inverters mentioned in Table 2, the ANAREDE program was used to calculate the voltage drops on the buses, caused by the occurrence of solid short circuits on electrically near buses. The results were then compared to the pre-set limits providing information about the effect caused in the inverters by short circuits throughout the rest of the subsystem [24].

Figure 6 - Voltage drop during single-phase fault

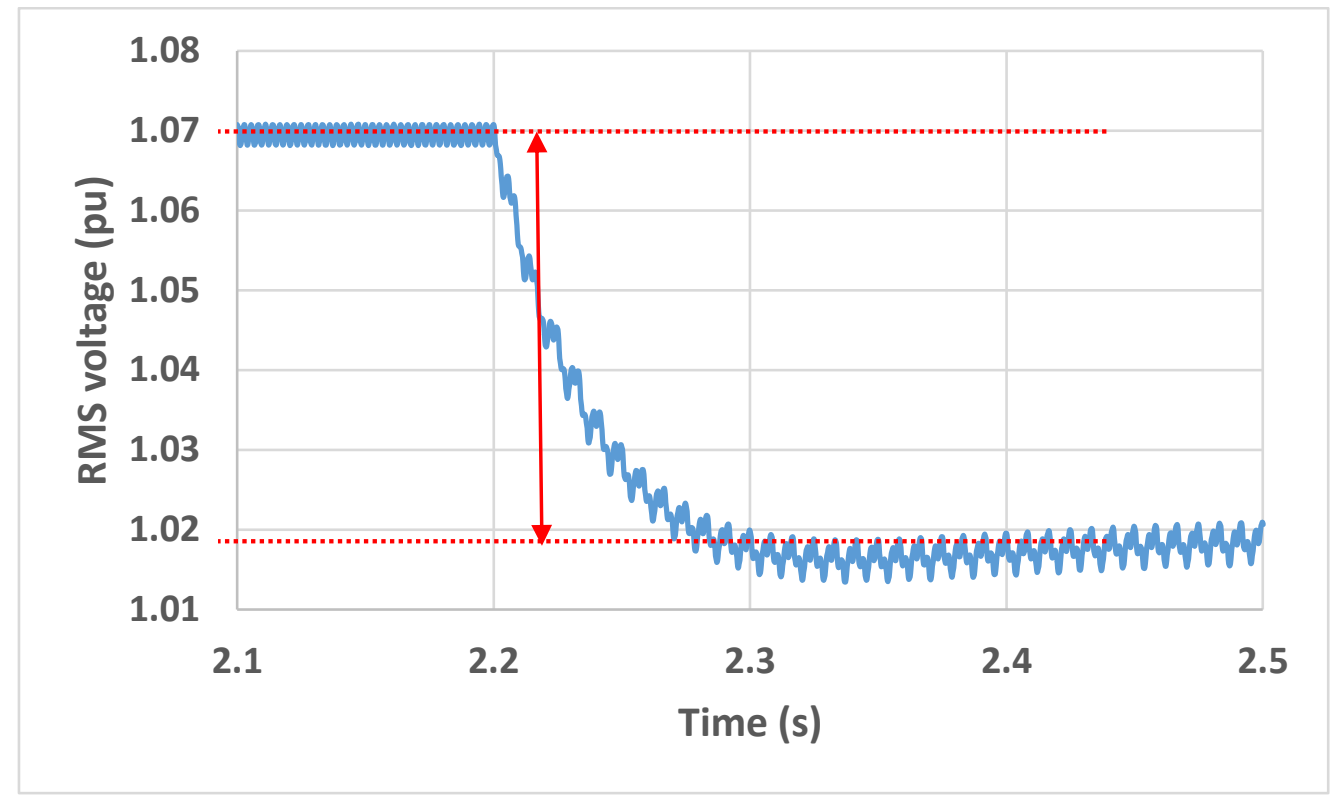

Source: Author

Comparing the results, it was determined whether a short circuit in a certain bus can cause misoperation of inverters and multi-infeed interaction in the system. After this first round of studies, it was decided to repeat the procedure but this time the use mitigation techniques: [24] 
- Increase in the steady state extinction angle of the inverters from $18^{\circ}$ to $24^{\circ}$ (see ANNEX D);

- Use of synchronous machines;

- Use of Statcoms.

The results were then taken to MATLAB, where it is possible to generate contour lines superposed on geographical maps indicating the critical areas of short circuit occurrence [16] [24] [25].

After all these tests, another kind of study was conducted in order to evaluate the magnitudes of the disturbances and oscillations caused in the multi-infeed network due to a three-phase short-circuit (the worst case of short-circuit) [26]. 
Figure 7 - Flowchart of the methodology

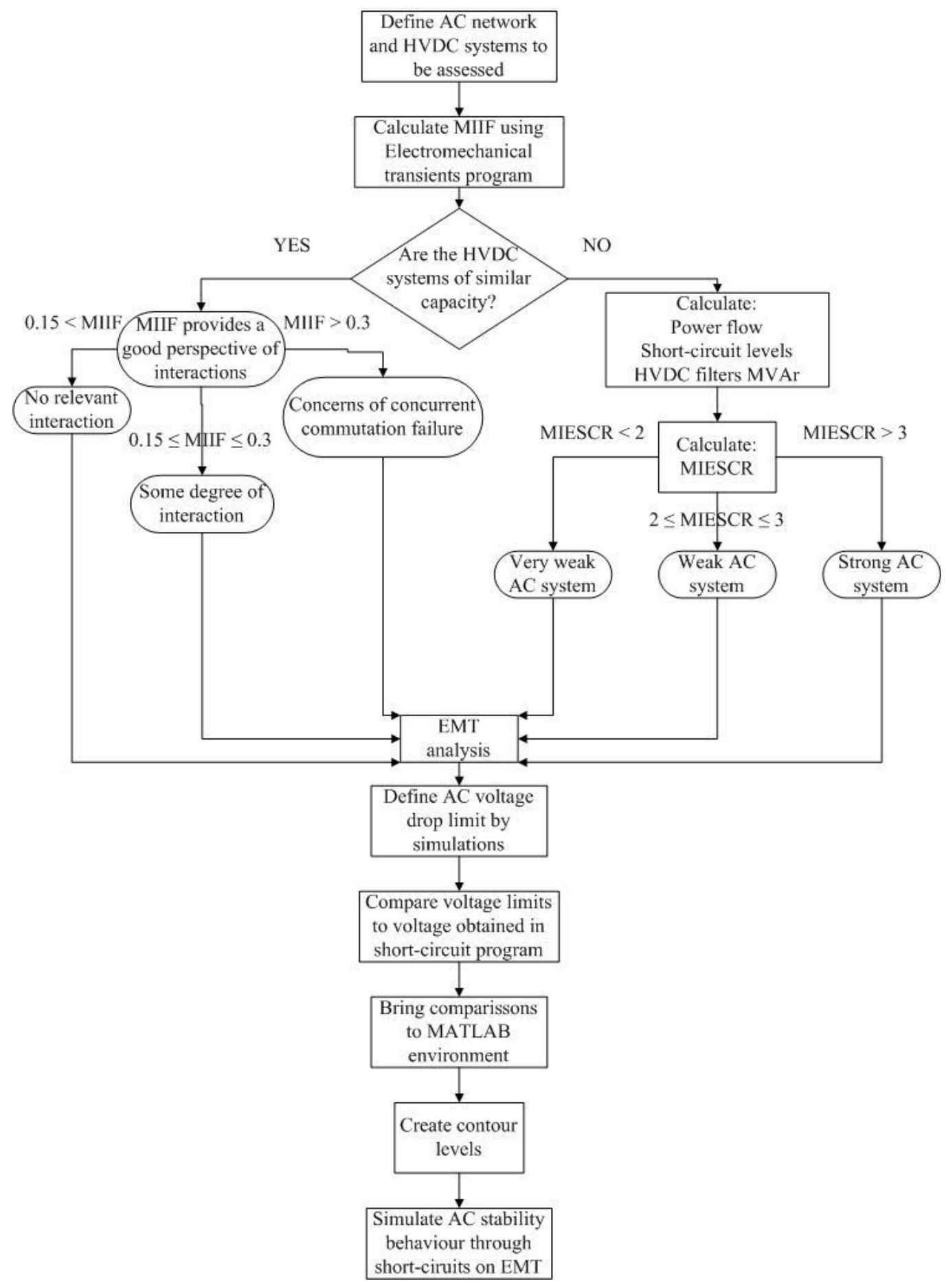

Source: Author 


\section{RESULTS}

This chapter presents the results obtained for the Brazilian power grid. In item 5.1 it is presented the results using the indicators as MIIF and MIESCR, as well as the stabilities and short-circuit studies, that will prove whether is necessary to deeply detail the analysis. In item 5.2 it is presented the maps of critical areas with regards of the critical short-circuit areas. Finally, item 5.3 presents the oscillatory behaviour of the system, evaluated under three-phase short-circuit in EMT program.

\subsection{Indicators Results}

The sequence of results presented begins with the MIIF and MIESCR indicators, as well as the stabilities and short-circuit studies, determined by [16] to assess the system behaviour.

\subsubsection{STABILITY AND SHORT-CIRCUIT STUDIES}

In this section, it is presented the indicators/factors used to evaluate the performance and interaction of HVDC systems and a Short-Circuit analysis of the 2020 Brazilian Power Grid. The presented indexes are the Multi-Infeed Interaction Factor (MIIF) and the Multi-Infeed Effective Short Circuit Ratio (MIESCR), for the Effective Short Circuit Ratio (ESCR) please check ANNEX E. Besides providing the short-circuit information for the obtainment of the ESCR and MIESCR indicators, the short-circuit studies were performed with the objective of locating the most critical buses in the system. Some buses may be more import than others in a Multi-infeed context, for instance voltage drops (short-circuits) in them may cause relevant voltage drops in many converter buses at the same time, for the results of these studies, please check ANNEX E.

\subsubsection{Multi-infeed Interaction Factor - MIIF}

In the next tables, it is presented the MIIF between the inverters, in the Brazilian power grid, according to the EPE, in the year of 2020. The MIIF was calculated using the power system stability software ANATEM. The studies were performed based on the ANATEM file, related to the 2020 Decennial Expansion Plan - DEP (PDE in Portuguese), and released by EPE. 
Table 3 - MIIF under different season and load conditions. a) Light load - North dry; b) Average load - Norht dry; c)Heavy load - North dry; d) Light load - Norht wet; e) Average load - North wet; f) Heavy load - North wet

a)

\begin{tabular}{c|c|c|c|c}
\hline \multicolumn{5}{c}{ Light load - North dry season } \\
\hline BUS & IB & TR & ES & AR \\
\hline IB & $100 \%$ & $26.0 \%$ & $25.3 \%$ & $34.2 \%$ \\
\hline TR & $27.9 \%$ & $100 \%$ & $33.3 \%$ & $29.3 \%$ \\
\hline ES & $34.5 \%$ & $42.0 \%$ & $100 \%$ & $39.1 \%$ \\
\hline AR & $45.1 \%$ & $35.9 \%$ & $37.8 \%$ & $100 \%$ \\
\hline
\end{tabular}

b)

\begin{tabular}{c|c|c|c|c}
\hline \multicolumn{5}{c}{ Average load - North dry season } \\
\hline BUS & IB & TR & ES & AR \\
\hline IB & $100 \%$ & $19.6 \%$ & $18.5 \%$ & $20.2 \%$ \\
\hline TR & $33.4 \%$ & $100 \%$ & $31.2 \%$ & $22.5 \%$ \\
\hline ES & $26.9 \%$ & $27.5 \%$ & $100 \%$ & $15.7 \%$ \\
\hline AR & $23.9 \%$ & $14.3 \%$ & $11.9 \%$ & $100 \%$ \\
\hline
\end{tabular}

c)

\begin{tabular}{c|c|c|c|c}
\hline \multicolumn{5}{c}{ Heavy load - North dry season } \\
\hline BUS & IB & TR & ES & AR \\
\hline IB & $100 \%$ & $21.2 \%$ & $21.8 \%$ & $33.4 \%$ \\
\hline TR & $30.1 \%$ & $100 \%$ & $28.8 \%$ & $27.8 \%$ \\
\hline ES & $38.3 \%$ & $34.3 \%$ & $100 \%$ & $39.1 \%$ \\
\hline AR & $50.7 \%$ & $29.7 \%$ & $34.1 \%$ & $100 \%$ \\
\hline
\end{tabular}

d)

\begin{tabular}{c|c|c|c|c}
\hline \multicolumn{5}{c}{ Light load - North wet season } \\
\hline BUS & IB & TR & ES & AR \\
\hline IB & $100 \%$ & $33.0 \%$ & $33.4 \%$ & $44.9 \%$ \\
\hline TR & $33.6 \%$ & $100 \%$ & $41.0 \%$ & $39.4 \%$ \\
\hline ES & $40.5 \%$ & $49.2 \%$ & $100 \%$ & $51.4 \%$ \\
\hline AR & $48.4 \%$ & $42.6 \%$ & $46.5 \%$ & $100 \%$ \\
\hline
\end{tabular}

e)

Source: Author

\begin{tabular}{c|c|c|c|c|}
\hline \multicolumn{5}{c}{ Heavy load - North wet season } \\
\hline BUS & IB & TR & ES & AR \\
\hline IB & $100 \%$ & $24.6 \%$ & $24.5 \%$ & $39.8 \%$ \\
\hline TR & $38.8 \%$ & $100 \%$ & $35.4 \%$ & $38.8 \%$ \\
\hline ES & $46.1 \%$ & $40.9 \%$ & $100 \%$ & $50.5 \%$ \\
\hline AR & $55.4 \%$ & $35.0 \%$ & $39.2 \%$ & $100 \%$ \\
\hline
\end{tabular}

f)

\begin{tabular}{|c|c|c|c|c|}
\hline \multicolumn{5}{|c|}{$d-$ No } \\
\hline BUS & IB & TR & ES & AR \\
\hline IB & & & & \\
\hline TR & & & & \\
\hline ES & & & & \\
\hline $\mathrm{AR}$ & $52.1 \%$ & $33.7 \%$ & $37.8 \%$ & $100 \%$ \\
\hline
\end{tabular}


The MIIF calculated for the various load flow conditions shows a possibly problematic multiinfeed interaction. Many of the MIIF values are in the range of 30\% - 50\% and some are above $50 \%$. The results indicate that converters will interact with each other.

\subsubsection{Multi-infeed Equivalent Short Circuit Ratio - MIESCR}

The MIESCR calculated is presented next.

Table 4 - MIESCR calculated with maximum and minimum short circuit values. a) Maximum short-circuit scenario; b) Minimum short-circuit scenario

a)

\begin{tabular}{c|c|c|c|c|c|c}
\hline \multicolumn{7}{c}{ MIESCR - MAXIMUM SHORT CIRCUIT } \\
\hline BUS & LL - ND & LL - NW & AL - ND & AL - NW & HL - ND & HL - NW \\
\hline IB & 2 & 1.8 & 2.1 & 2 & 2 & 1.8 \\
\hline TR & 2.8 & 2.3 & 3 & 2.5 & 2.9 & 2.3 \\
\hline ES & 2.3 & 1.8 & 2.5 & 2.1 & 2.4 & 1.9 \\
\hline AR & 2 & 1.6 & 1.9 & 1.7 & 1.9 & 1.7 \\
\hline
\end{tabular}

Source: Author

b)

\begin{tabular}{c|c|c|c|c|c|c}
\hline \multicolumn{7}{c}{ MIESCR - MINIMUM SHORT CIRCUIT } \\
\hline BUS & LL - ND & LL - NW & AL - ND & AL - NW & HL - ND & HL - NW \\
\hline IB & 1.7 & 1.5 & 1.7 & 1.7 & 1.7 & 1.5 \\
\hline TR & 2 & 1.7 & 2.2 & 1.8 & 2.1 & 1.6 \\
\hline ES & 1.7 & 1.3 & 1.9 & 1.5 & 1.8 & 1.4 \\
\hline AR & 1.6 & 1.2 & 1.5 & 1.3 & 1.5 & 1.3 \\
\hline
\end{tabular}

Source: Author

The ESCR (ANNEX E) values obtained suggest that all HVDC systems operates comfortably. However, looking at Table 4 the MIESCR indicates a very problematic situation. The system short circuit capacity is shared among the converters and the net result 
is a relatively weak AC system that may be unable to sustain all the HVDC systems. This situation supports the use of the proposed methodology.

\subsection{Mapping of critical short-circuits areas}

The proposed methodology is hereon applied by the determination of the geo-electrical maps of the critical short-circuit area of the Brazilian Southeast region. A series of events were simulated to create a range that is sufficiently diverse to evaluate the consequential commutation failure.

Events are described in Table 5

Table 5 - Events simulated for short-circuit mapping

\begin{tabular}{|c|c|c|c|c|c|c|}
\hline Event & Faulted bus & $\begin{array}{c}Z_{\text {FAULT }} \\
(\mathrm{H})\end{array}$ & $\mathrm{Z}_{\text {MINIMUM }}(\mathrm{H})$ & Failed inverters & Inverter extra shunt (MVAr) & $\begin{array}{l}\Delta \mathrm{V} \\
(\%)\end{array}$ \\
\hline 1 & Araraquara2 & 0.304 & 0.305 & ALL & - & 7.1 \\
\hline 2 & Estreito & 0.273 & 0.272 & $\overline{A L L}$ & - & 8.1 \\
\hline 3 & Terminal Rio & 0.32 & 0.321 & $A R, I B, T R$ & - & 12.9 \\
\hline 4 & Terminal Rio & 0.319 & 0.321 & ALL & - & 13 \\
\hline 5 & Ibiuna & 0.155 & 0.156 & ALL & - & 5.9 \\
\hline 6 & Araraquara2 & 0.137 & 0.138 & $\mathrm{MA}$ & 233 & 12.4 \\
\hline 7 & Araraquara2 & 0.038 & 0.138 & $A R, E S$ & 233 & 29.8 \\
\hline 8 & Araraquara2 & 0.034 & 0.138 & ALL & 233 & 31.5 \\
\hline 9 & Estreito & 0.126 & 0.127 & ES & 233 & 12.9 \\
\hline 10 & Estreito & 0.036 & 0.127 & $A R, E S, T R$ & 233 & 34.9 \\
\hline 11 & Terminal Rio & 0.164 & 0.165 & TR & 233 & 18.4 \\
\hline 12 & Terminal Rio & 0.038 & 0.165 & $\mathrm{AR}, \mathrm{ES}, \mathrm{TR}$ & 233 & 38.9 \\
\hline 13 & Terminal Rio & 0.003 & 0.165 & ALL & 233 & 91 \\
\hline 14 & Ibiuna & 0.063 & 0.064 & IB & 233 & 16.3 \\
\hline 15 & Ibiuna & 0.01 & 0.064 & $\overline{A L L}$ & 233 & 20.1 \\
\hline 16 & Araraquara2 & 0.255 & 0.256 & $\overline{A L L}$ & SyncMach 3x300MVAr & 7.3 \\
\hline 17 & Estreito & 0.235 & 0.236 & ALL & SyncMach 3x300MVAr & 8 \\
\hline 18 & Terminal Rio & 0.284 & 0.285 & ALL & SyncMach 3x300MVAr & 13.1 \\
\hline 19 & Ibiuna & 0.162 & 0.163 & ALL & SyncMach 3x300MVAr & 6 \\
\hline 20 & Araraquara2 & 0.281 & 0.282 & ALL & Statcom 900MVAr & 7.3 \\
\hline 21 & Estreito & 0.278 & 0.279 & ALL & Statcom 900MVAr & 8 \\
\hline 22 & Terminal Rio & 0.368 & 0.369 & $\overline{A L L}$ & Statcom 900MVAr & 13.1 \\
\hline 23 & Ibiuna & 0.155 & 0.156 & ALL & Statcom 900MVAr & 6 \\
\hline
\end{tabular}

Source: Author 
Where:

- Event is the number given to the event simulated;

- Power transmitted is the power transmitted in the HVDC link;

- Inverter type is the type of inverter operating at the HVDC links;

- $\quad \gamma$ is the extinction angle of the inverters;

- $\mathrm{Z}_{\mathrm{FAULT}}$ is the first impedance fault that causes commutation failure;

- $\mathrm{Z}_{\text {MINIMUM }}$ is the last impedance fault that causes no commutation failure

- Failed inverters are the inverters that fail in each case;

- Rectifier/Inverter extra shunt is the extra compensation necessary applied to the converters to ensure correct operation in each case;

- $\Delta \mathrm{V}$ is the percentage voltage drop on the inverter bus that causes commutation failure.

\subsubsection{LCC operating with $\gamma=18^{\circ}$}

Lines 1 to 5 in Table 5 show the details of the events simulated. The results follow the guidance described in the Methodology chapter and are rendered in the following maps.

The analysis presented here are only for solid single-phase short circuits, since they are the major part of the faults in transmission lines. Table 6 presents the limits of voltage sag in the inverters buses. Values greater than those shown will cause all inverters to fail.

Figure 8 and Figure 9 show the maximum and minimum system short circuit scenarios, respectively. The main difference between scenarios is the greater short circuit power available, what can be seen as a more robust system, or a system with a higher Short Circuit Ratio (SCR).

Table 6 - Voltage drop limits of commutation failure (\%)

\begin{tabular}{c|c|c|c|c}
\hline$\gamma$ & AR & IB & ES & TR \\
\hline $18^{\circ}$ & 7.1 & 5.9 & 8.1 & 12.9 \\
\hline
\end{tabular}

Source: Author

The yellow spots indicate the geographical areas where short circuits would have greater consequences, leading to simultaneous commutation failure in all the inverters. 
Figure 8 - Critical areas on maximum short circuit scenario $\left(18^{\circ}\right)$

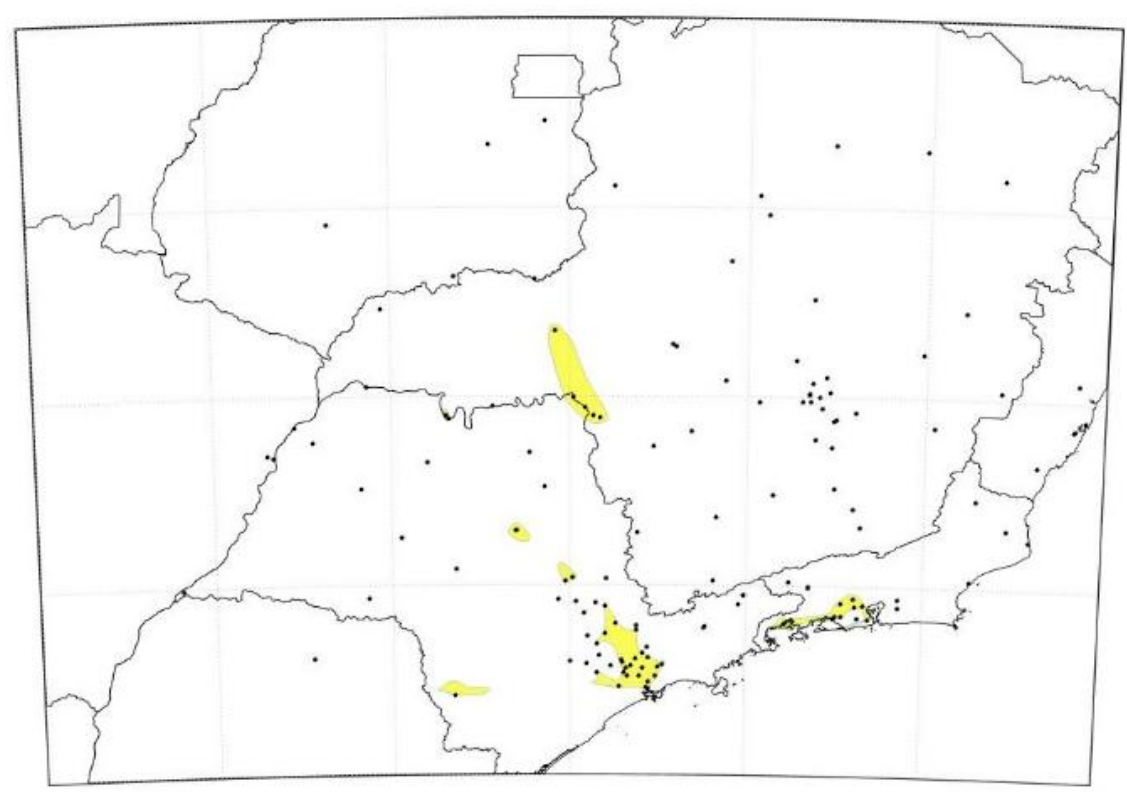

Source: Author

Figure $9-$ Critical areas on minimum short circuit scenario $\left(18^{\circ}\right)$

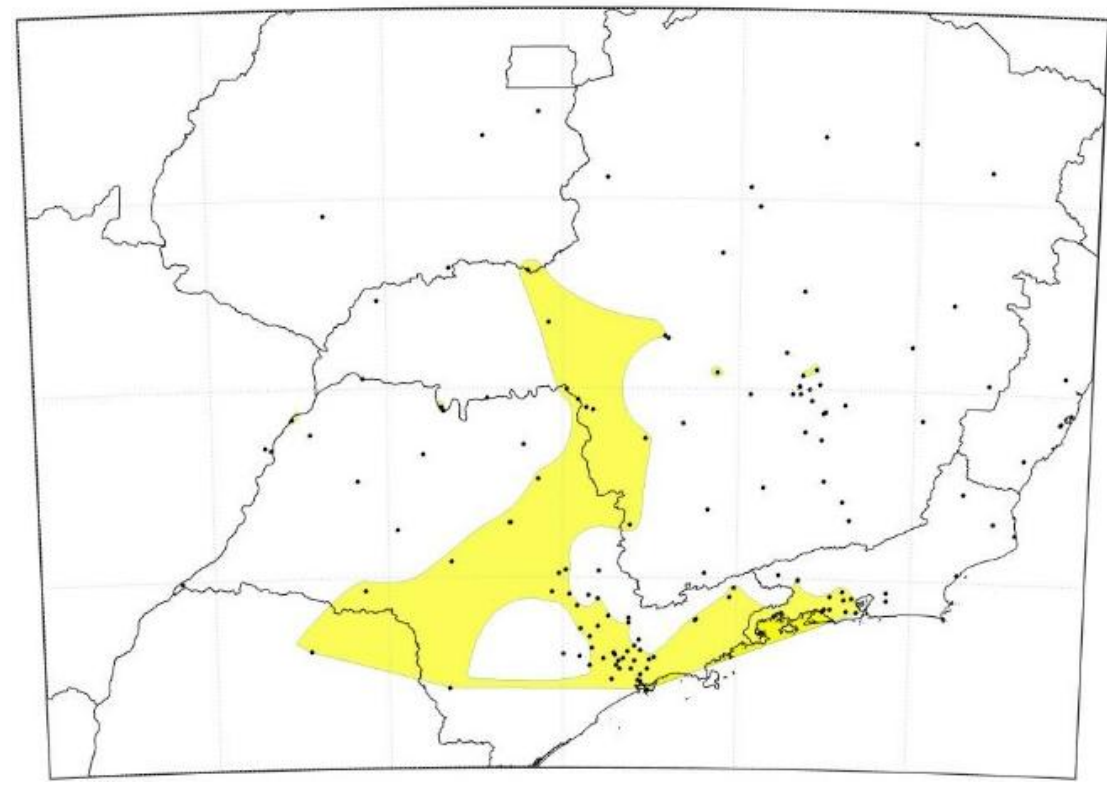

Source: Author

By analysing the figures above, it is possible to confirm that the worst areas of short circuit are closer to the biggest loads, near to many important transmission lines or near to the inverters buses. 


\subsubsection{Increased extinction angle}

Here is discussed the adoption of a larger steady state extinction angle $\left(18^{\circ}\right.$ to $\left.24^{\circ}\right)$ and how this influences the resilience of the inverters. All the changes necessary for a proper operation of the converters were made, for example the increase in the reactive power at the inverter bus.

It is worth noting that a larger extinction angle results in a lower DC voltage, effectively derating the converter. Also, it increases valve losses and snubber circuit stress, meaning that there is a cost involved.

A larger extinction angle provides more time for thyristors in the converters to re-establish its current blocking capacity, reducing the odds of commutation failure and therefore making the system more reliable.

Two important outcomes identified are:

- The inverters do not fail all together at the new limit established on EMT simulation, instead a commutation failure in one of them will not necessarily cause commutation failure on the others, a clear reduction of the multi-infeed effects;

- Different limits of commutation failure are notable.

\section{a) Mapping of new limits multiple commutation failure $\left(\gamma=24^{\circ}\right)$}

Next figures present the areas where a short circuit can lead to failure in one or more inverters. The blue spots represent the areas where a short circuit will lead to commutation failure in only one inverter. The colorbar on the right side indicates the number of inverters affected. The figures have few areas that correspond to points where two or more inverters can simultaneously fail. 
Figure 10 - Critical areas on maximum short circuit scenario $\left(\gamma=24^{\circ}\right)$

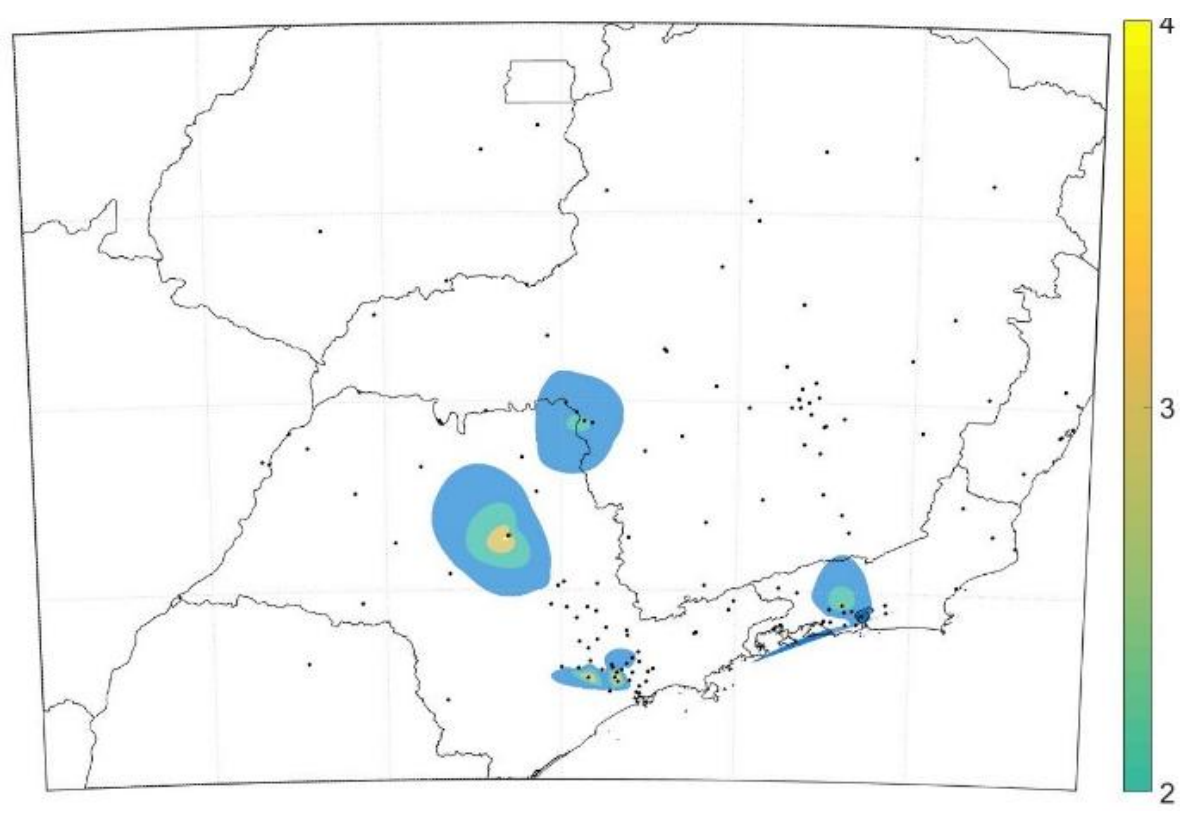

Source: Author

Figure 11 - Critical areas on minimum short circuit scenario respectively $\left(\gamma=24^{\circ}\right)$

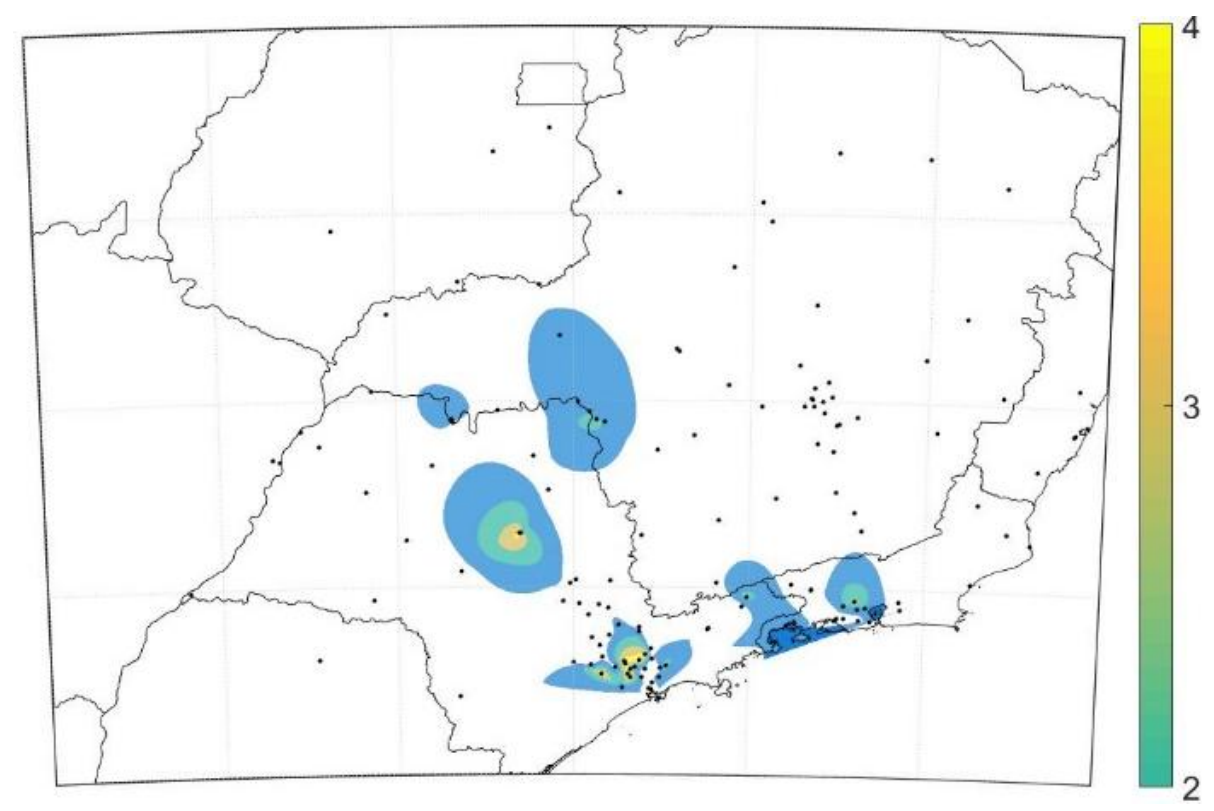

Source: Author

When comparing figures 9 and 10 to the ones in the section 5.2.1, it is evident the reduction of simultaneous commutation failure by the reduction of the yellow areas, indicating a 
reduction in problematic areas due to a stronger converter (less susceptibility to commutation failure).

The blue areas are highlight some important points in the Brazilian transmission system, for example buses close to the cities of Rio de Janeiro and Sao Paulo, the largest cities of Brazil.

\section{b) New pattern of limits for distinct levels of multiple commutation failure $\left(\gamma=24^{\circ}\right)$}

The resilience increase was notable and the difference in voltage drop limits can be seen in Table 7, where the $\gamma=18^{\circ}$ line presents the limits of voltage drop before simultaneous commutation failure in all the inverters and the $\gamma=24^{\circ}$ represents the limits of voltage drop before commutation failure in only one inverter.

Table 7 - Initial limits for voltage drop before commutation failure (\%)

\begin{tabular}{c|c|c|c|c}
\hline$\gamma$ & $\mathrm{AR}$ & $\mathrm{IB}$ & $\mathrm{ES}$ & $\mathrm{TR}$ \\
\hline $18^{\circ}$ & 7.1 & 5.9 & 8.1 & 13 \\
\hline $24^{\circ}$ & 12 & 13 & 13 & 18 \\
\hline
\end{tabular}

Source: Author

Besides these limits, the system with greater extinction angle can have other limits of voltage drop where multiple commutation failures are felt by the system and two or more inverters experience simultaneous commutation failure. That situation exists when reducing even more the fault impedance and is shown in Table 8, where the empty cells represent situations that were not found on simulations. Notice the complementarity between Table 7 and Table 8.

Table 8 - Voltage drop limits for different situations of failure (\%)

\begin{tabular}{c|c|c|c|c}
\hline \#INVERTERS FAILING & AR & IB & ES & TR \\
\hline 1 & 12.4 & 16.3 & 12.9 & 18.4 \\
\hline 2 & 29.8 & - & - & - \\
\hline 3 & - & - & 34.9 & 38.9 \\
\hline 4 & 31.5 & 20.1 & - & 91.0 \\
\hline
\end{tabular}

Source: Author 


\subsubsection{Use of synchronous condensers or Statcoms on inverters buses}

Two new different systems were assembled here, one contains only synchronous condensers, three for each inverter bus ( $3 \mathrm{X} \pm 300 \mathrm{MVAr}$ rated power) and the other only Statcoms, one for each inverter bus (1X $\pm 900 \mathrm{MVAr})$.

The results of both systems are pretty similar to each other and are described by the same figures below. The voltage drop tables are similar to Table 6 but this case presents a reduction of yellow areas when compared to the base case, but unlike the increase in the extinction angle, the use of condensers and Statcoms will enhance the system and not the converters.

Figure 12 - Critical areas on maximum short circuit scenario (Synchronous/Statcom)

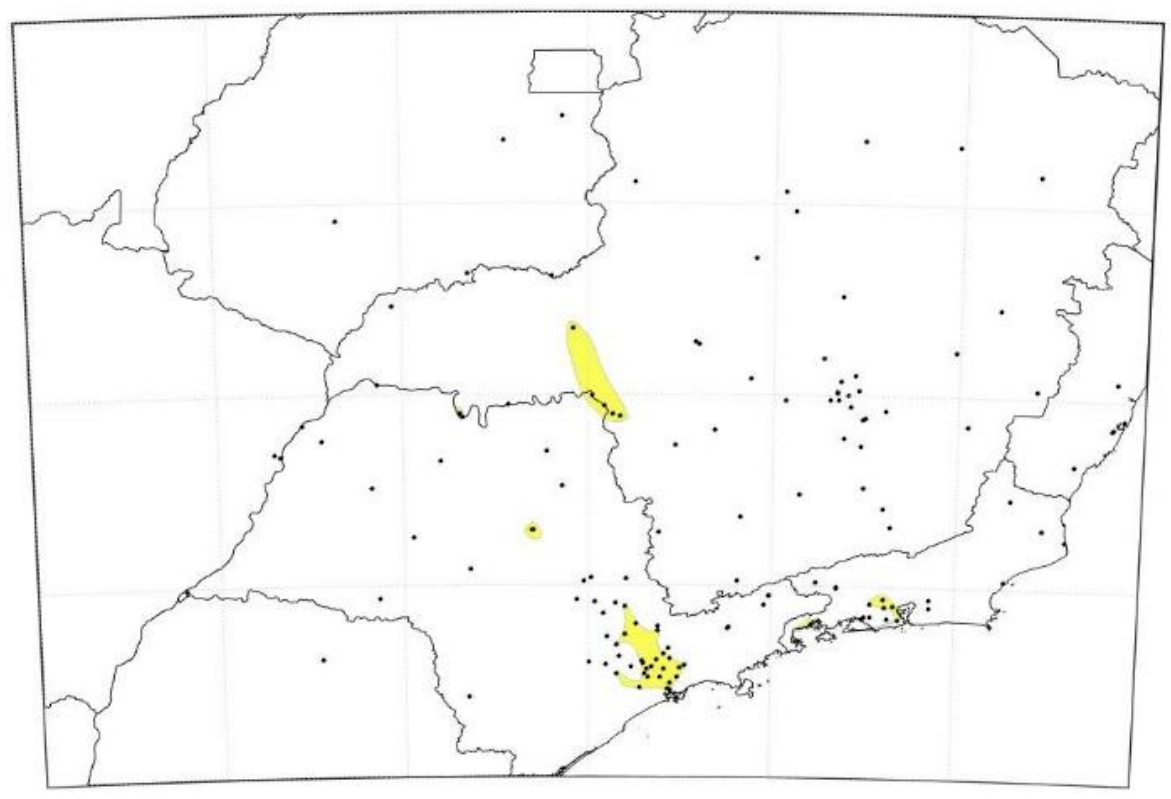

Source: Author 
Figure 13 - Critical areas on minimum short circuit scenario (Synchronous/Statcom)

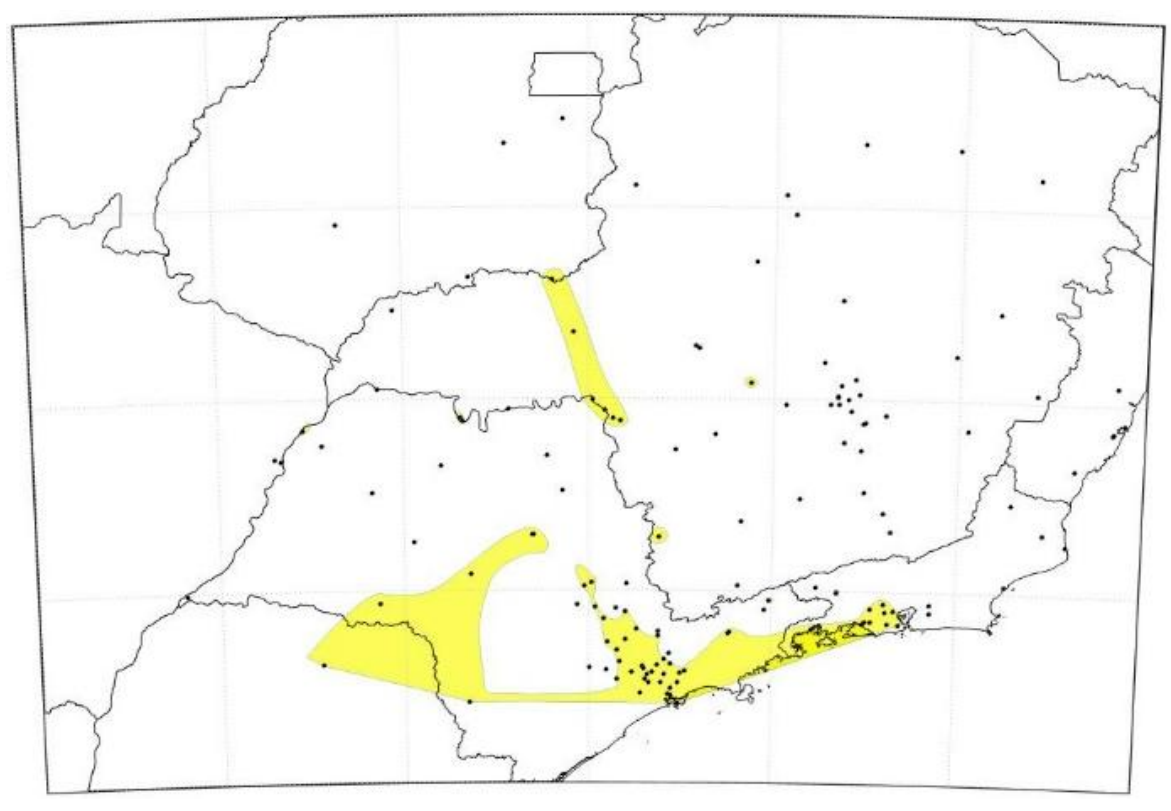

Source: Author

\subsection{DYNAMIC PERFORMANCE: FAULT APPLICATION}

After all the results presented, this section means to evaluate the overall system dynamic performance after disturbances such as short-circuits. These results are of first importance to show how worrisome is the multi-infeed interaction evaluated during the studies.

As will be seen in the next results, even if the consequential commutation failure is a problematic and worrisome situation, the system proved to be stable and capable of recovering from a three-phase solid short-circuit.

\subsubsection{Performance Comparison: Machines and Equivalents - Three-Phase Short- Circuit}

In this section, it is presented a comparison between two different situations regarding the multi-infeed and electromechanical stability studies, simulated on PSCAD and described next. [26]

1. EPE original system, with only equivalent sources representing the generation on the north and southeast subsystems. (blue lines on the graphs) 
2. Modified EPE original system, with equivalent sources and synchronous machines representing the generation on the north and southeast subsystems. (green lines on the graphs)

The synchronous machines represent the generation of around $18717 \mathrm{MW}$ in the north and $16282 \mathrm{MW}$ in the southeast. A large amount of the analysed power generation of Brazil are in the Northern and Southeast subsystems and the representation of the dynamics of its power plants may be important, since the two subsystem are connected through HVDC links. It is reasonable to believe that the inclusion of these machines may allow a better evaluation of the multi-infeed phenomena.

The original EPE system was modified so the four HVDC links (ITAIPU, RIO MADEIRA, BELO MONTE 1 and BELO MONTE 2) operate at rated voltage and current, and at or near rated power. It was included machines models representing important power plants (listed in Table 9). For simplicity, initially, the machines have constant torque and it is used a generic voltage regulator. Faithfully representing all the elements of the power plant requires much work and would be unproductive, as the extra detailing will not produce significant differences, so there is no turbine dynamics or PSS for further reference, please check ANNEX G. The simplifications are enough for the simulations and also conservative because the power plants operating with simplified controls tend to be worse in performance. In order to maintain the same system overall short-circuit level, the system equivalents were adjusted. The voltage magnitude of the ideal sources and the short-circuit impedance of the equivalent sources were modified, the ideal sources phases were also modified to adjust power flow. To maintain a good voltage RMS value among the AC buses the transformers tap were also adjusted. The included power plants are presented in Table 9.

Table 9 - Power Plants represented as Machines in the PSCAD.

\begin{tabular}{c|c|c}
\hline $\begin{array}{c}\text { \#BUS } \\
\text { (ANAREDE) }\end{array}$ & POWER PLANT & S(MVA) \\
\hline 3581 & Angra I & 760 \\
\hline 3582 & Angra II & 1458 \\
\hline 195 & Pimental-Belo Monte & 246 \\
\hline 4941 & Belo Monte & 12834 \\
\hline
\end{tabular}




\begin{tabular}{|c|c|c|}
\hline 1426 & Emborcação & 1254 \\
\hline 3587 & Furnas & 1280 \\
\hline 2041 & Ilha Solteira & 3572 \\
\hline 3637 & Itaipu 50 & 7370 \\
\hline 3584 & Itaipu 60 & 7370 \\
\hline 2045 & Porto Primavera & 1568 \\
\hline $50 / 52 / 54$ & Tucurui I & 4200 \\
\hline $70 / 71$ & Tucurui II & 4290 \\
\hline 89 & Xingo & 3120 \\
\hline 3586 & L. C. Barreto & 1104 \\
\hline 3588 & Marimb & 1520 \\
\hline 1001 & Averml & 1500 \\
\hline 3592 & Itumb & 2190 \\
\hline
\end{tabular}

Source: Author

The graphs and figures of this section and of ANNEX F adopt the following nomenclature:

- Belo Monte systems 1 and 3 are the Belo Monte system rectifiers.

- Belo Monte systems 2 and 4 are the Belo Monte system inverters.

- Madeira system 1 is the Madeira system rectifiers.

- Madeira system 2 is the Madeira system inverter.

- Itaipu system 2 is the Itaipu system rectifier.

- Itaipu system 2 is the Itaipu system inverter.

- Belo Monte system 2 is the Belo Monte bipole ending in Estreito.

- Belo Monte system 4 is the Belo Monte bipole ending in Terminal Rio.

The comparison should give an idea of how the control model and machines inertia influence the network performance.

All the results shown in the following graphs present a solid, $80 \mathrm{~ms}$, three-phase fault starting at 1.2 seconds at the Araraquara $500 \mathrm{kV}$ bus (Rio Madeira HVDC inverter station). 


\subsubsection{Power dispatched on the HVDC links}

The following graphs present the incoming power at the inverters of the three HVDC links, Belo Monte, Madeira and Itaipu.

Systems return to stability in about $0.5 \mathrm{~s}$. It can also be seen that the Madeira system, where the short circuit is located, presents a secondary disturbance during its recovery period.

The consequences of a consequential commutation failure starting at the Araraquara2 bus can be seen in Ibiuna, Estreito and Terminal Rio buses in ANNEX F.

Figure 14 - Power on Belo Monte bipole 1

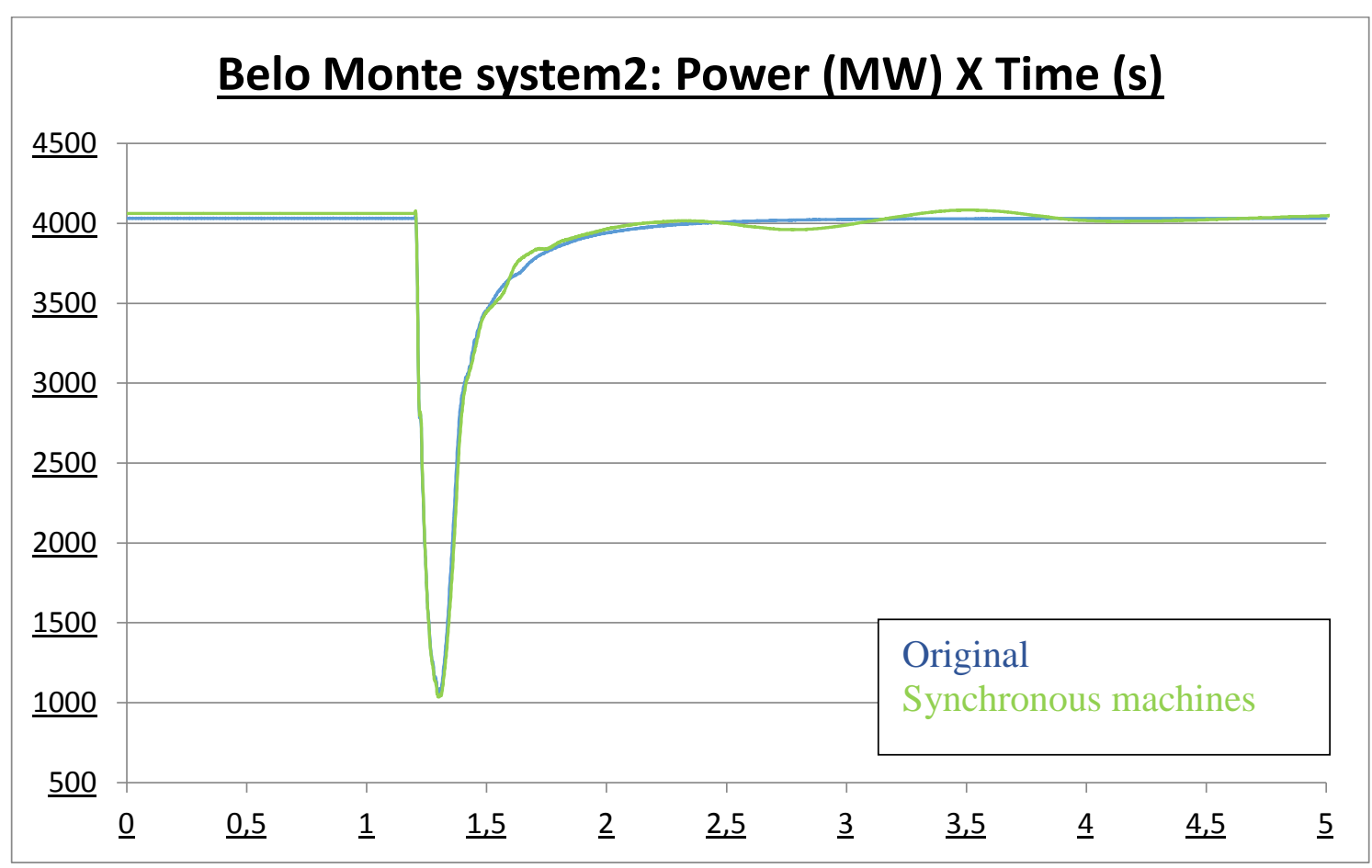

Source: Author 


\subsubsection{Inverter DC voltages}

The following charts present the DC voltage at the inverters of the three HVDC links, Belo Monte, Madeira and Itaipu.

The oscillatory behaviour, noted on the green lines (systems presenting machines), are due to the machines inertia. Both cases return to its stability initial state, however the oscillations on the green line show a pattern that makes the system with machines recover slower.

Figure 15 - Voltages on Belo Monte inverter system 2 pole 1

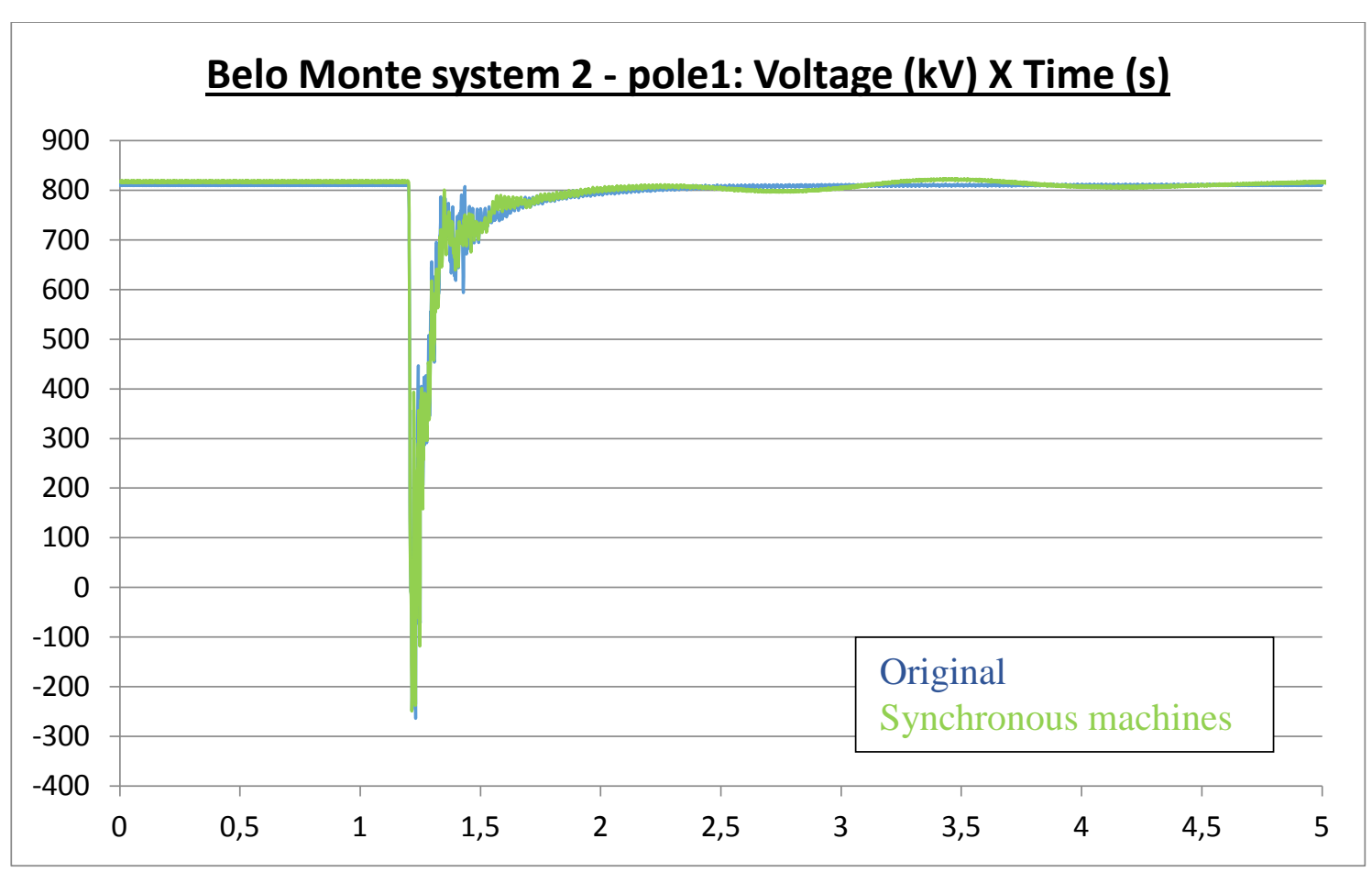

Source: Author 


\subsubsection{Inverter AC voltages}

The following graph presents the AC voltage at the inverter bus of Belo Monte (Estreito).

The graph indicates an excellent match between both cases, indicating that the comparison is acceptable. It also indicates that all the buses have at least $\approx 20 \%$ of variation on its AC voltage, which is a good indicator of commutation failure.

Figure 16 - Estreito AC bus voltage (Belo Monte system 2)

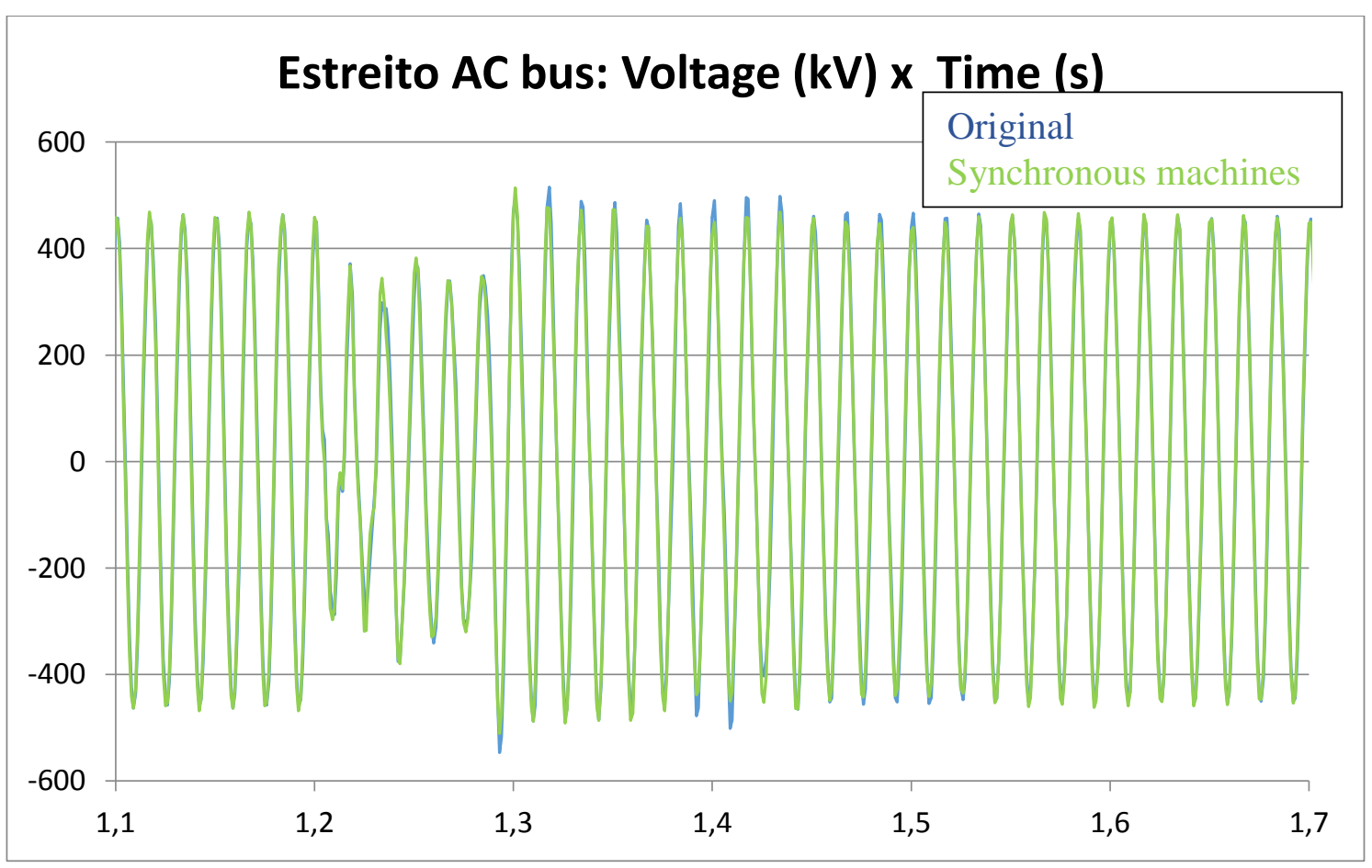

Source: Author 


\subsubsection{Alpha on the rectifiers}

The firing angle on the rectifiers defines the DC current, which should be constant. These angles are represented below.

All rectifier systems operate at around $15^{\circ}$, which guarantees some angle margin in case there is a sudden change in the $\mathrm{AC}$ voltage both in the inverter or rectifier AC system. The Madeira system presents the same disturbances during the recovery period, already showed before.

Figure 17 - Alpha on Belo Monte rectifier system 1 pole 1

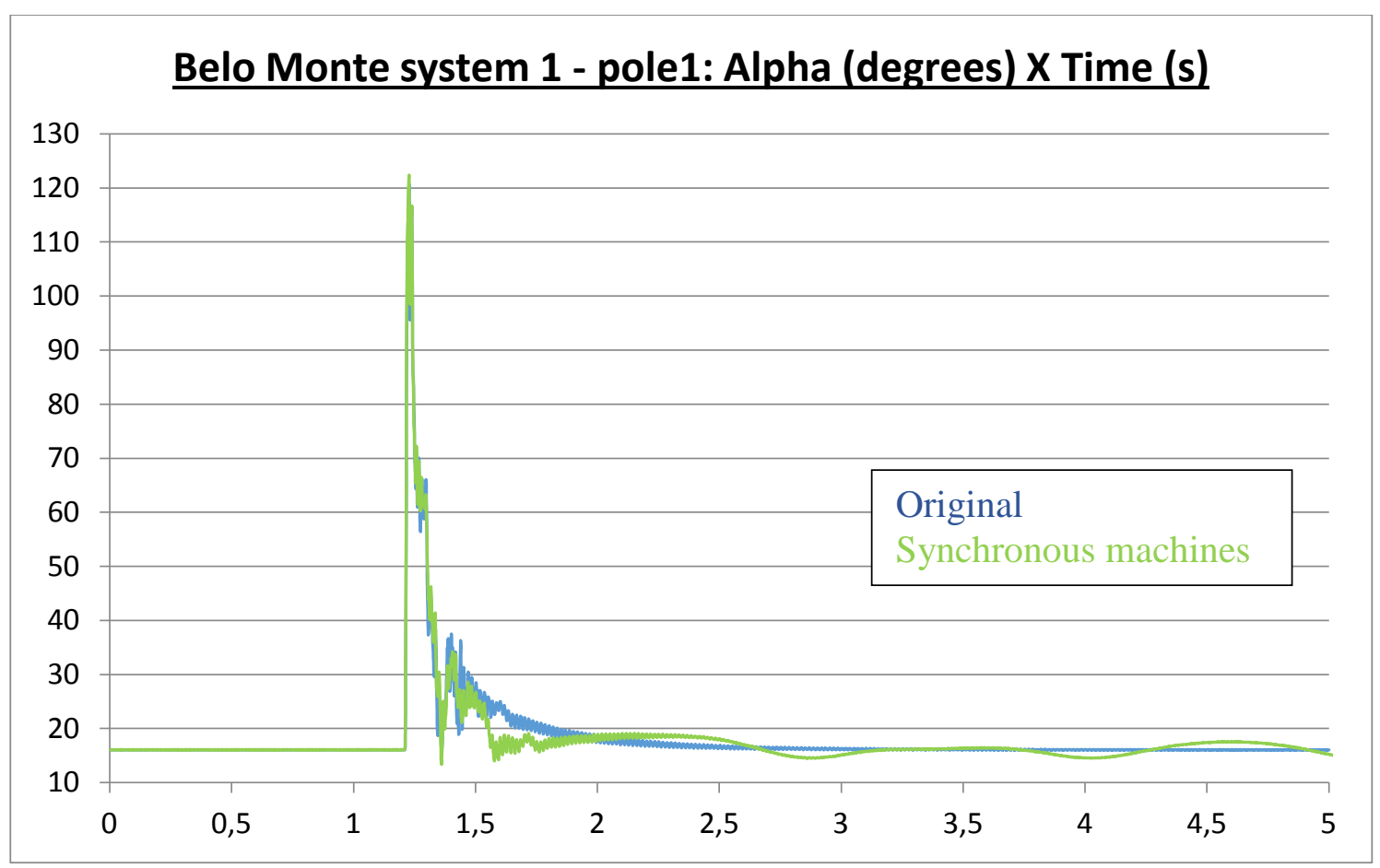

Source: Author 


\subsubsection{Alpha on the inverters}

The firing angle on the inverters defines the DC voltage, which must be as close to rated voltage as possible. This angle is represented below.

Behaviour of inverters in both cases is quite equal, indicating that in both situations the inverters absorb the same amount of power.

Figure 18 - Alpha on Belo Monte Inverter system 2 pole 1

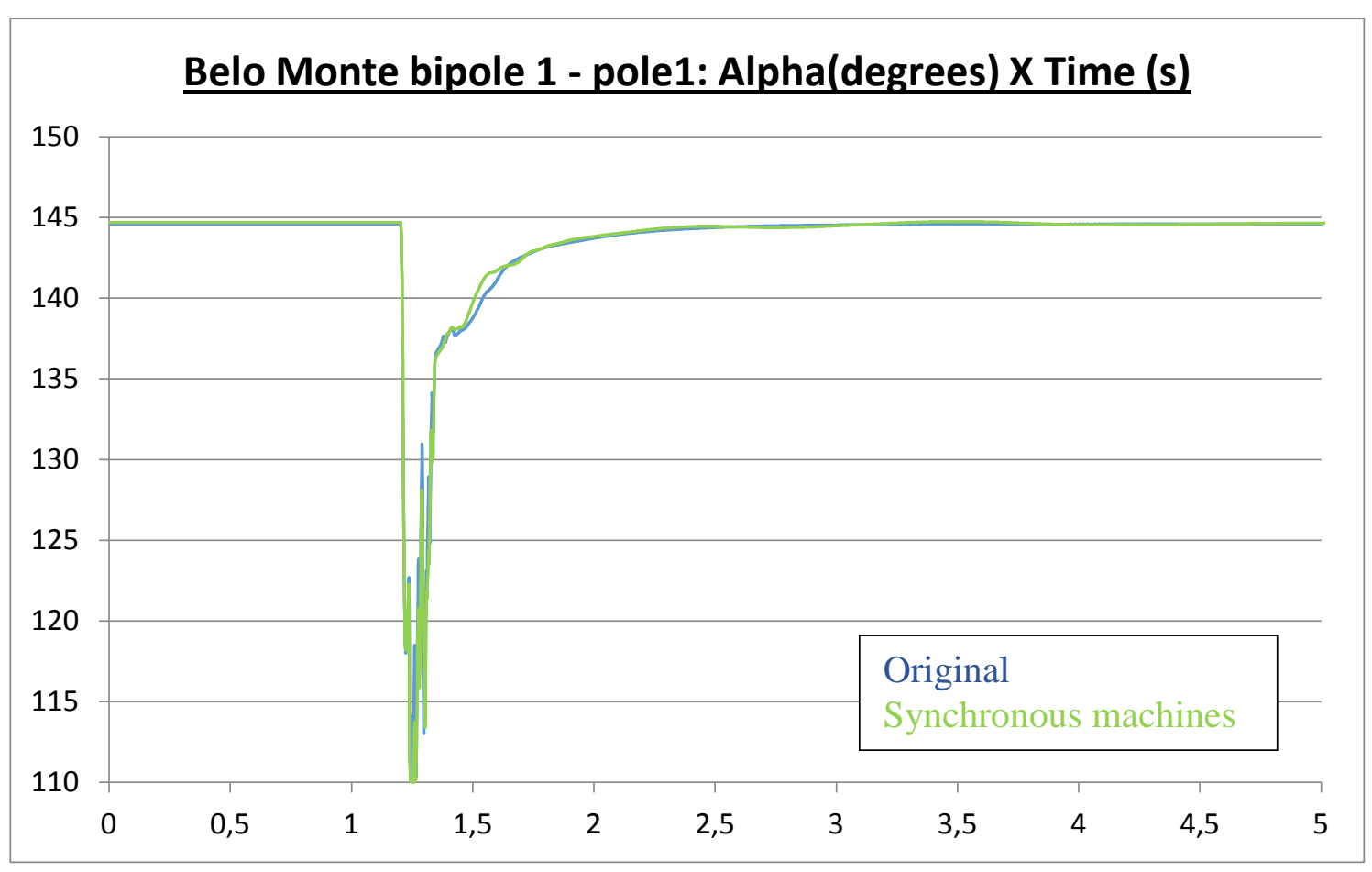

Source: Author 


\subsubsection{Power on the represented power plants}

The graph below presents the power (pu) dispatched at same of the most important machines represented in the system.

Figure 19 - Power on the machines after solid short-circuit at Araraquara 2 AC bus

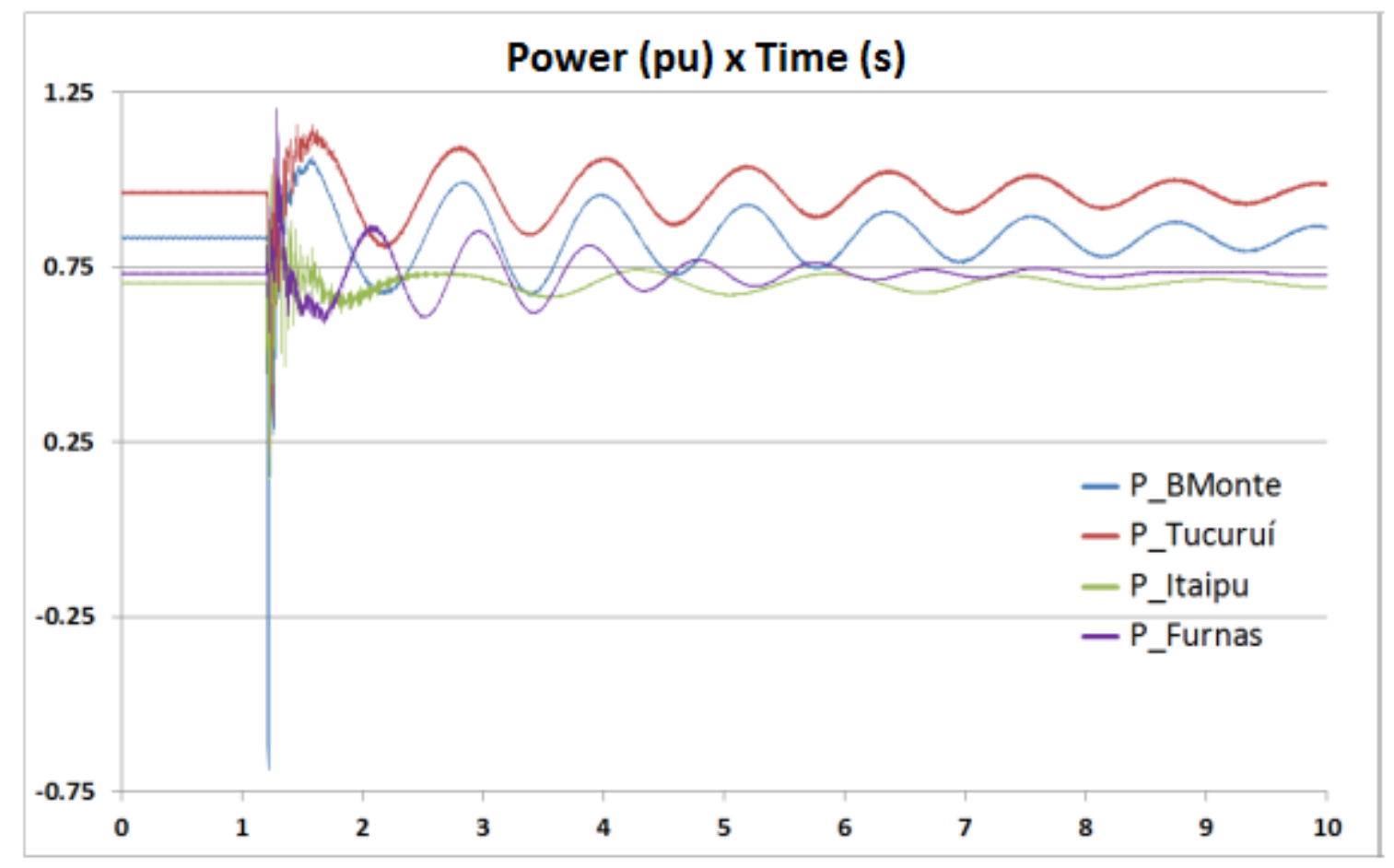

Source: Author

The oscillations seen on the machines dispatched power due to the short circuit are well damped and the system returns to its steady state, resuming their initial conditions. 


\section{CONCLUSIONS}

In this dissertation, the application of a different systematic method of commutation failure assessment, applied to the comparison of different mitigation methods in multi-infeed analysis is proposed to enhance former analysis, presented by [16], which would not perfectly take into account the performance of non-linarites, electromagnetic transients, for example. In addition to that, this new method permits a faster and wider analysis, since short circuit programs can represent a complete transmission system more easily and are faster to run than the same model represented in EMT programs.

The electro-geographical representation is expected to provide a large amount of information in a single figure and therefore simplify the assessment of information. The use of greater extinction angles, synchronous machines and Statcom as mitigation methods were also assessed and can be compared to original values of system operation. The comparison of the maps shows how powerful is the representation of critical areas through geo-electric maps.

Nevertheless, after all the discussion about the concurrent (consequential) commutation failure, the system stability was tested under short circuits applied directly to the Araraquara 2 AC bus, which was the most affected bus during tests. The system proved to be stable when operating with synchronous generators, confirming that the recovery time stablished by [16] was attended. 


\section{BIBLIOGRAPHY}

[1] Brazilian Government, "website," [Online]. Available: http://www.brasil.gov.br/infraestrutura/2011/12/potencial-hidreletrico-brasileiro-estaentre-os-cinco-maiores-do-mundo. [Acesso em 1707 2017].

[2] E. W. Kimbark, Direct current transmission, Portland, Oregon: John Wiley \& Sons, Inc., 1971.

[3] J. Arrillaga, Y. Liu e N. R. Watson, Flexible Power Transmission: The HVDC Options, England: 1 edition. John Wiley \& Sons., 2007.

[4] W. Komatsu, L. Matakas Junior e W. Kaiser, Handout of power electronics I, 2014.

[5] EPE, " Transmission data," [Online]. Available: http://www.epe.gov.br/Transmissao/Paginas/EPEdisponibilizaarquivos.aspx?CategoriaI $\mathrm{D}=$. [Acesso em 2507 2016].

[6] MISO Energy, "State of the Art" Transmission Planning HVDC Technology, February $19,2015$.

[7] Y. Rosenblum de Souza, "Analysis of the interaction amongst DC links in electrically close networks, Master degree dissertation (in Portuguese language)," Rio de Janeiro, 2014.

[8] V. F. Lescale, "Modern HVDC: State of the art and development trends," ABB Power Systems $A B$, p. 5.

[9] W. Hammer, "Dynamic Modeling of Line and Capacitor Commutated Converters for HVDC Power Transmission,” Zurich, 2003.

[10] Siemens, "Energy [Online]. Website," Available: https://www.energy.siemens.com/ru/en/power-transmission/hvdc/applicationsbenefits/hvdc-benefits.htm\#content=Economic\%20Aspects. [Acesso em 1107 2017].

[11] Cigré WG 14.07/IEEE WG 15.05.05, “TB 68 - GUIDE FOR PLANNING DC LINKS TERMINATING AT AC SYSTEMS LOCATIONS HAVING LOW SHORTCIRCUIT CAPACITIES,” Paris, France, 1992.

[12] J. F. Graham, T. Holmgren, P. Fischer e N. L. Shore, "The Rio Madeira HVDC System - Design aspects of Bipole 1 and the connector to Acre-Rondônia," em Cigré B4-111, 
Paris, 2012.

[13] R. Teixeira Pinto, "MULTI-TERMINAL DC NETWORKS - SYSTEM INTEGRATION, DYNAMICS AND CONTROL,” Torino, 2014.

[14] F. R. V. de A. Pedroso, M. T. Bassini, J. A. Jardini, S. Giuseppe Di Santo e e. al., "Multi-Infeed analysis of the Brazilian electrical system (in Portuguese language)," XXIV SNPTEE, p. 9, 2017.

[15] EPE, "Expansion of the interconnection between the North/Northeast and Southeast/Center-West regions of Brazil (in English)," Rio de Janeiro, 2014.

[16] Cigre Working Group B4.41, "Systems with multiple DC infeed,” December, 2008.

[17] Y. Shao e Y. Tang, "Fast Evaluation of Commutation Failure Risk in Multi-infeed HVDC Systems," IEEE Transactions on Power Systems, p. 8, 2017.

[18] J. Sreedavi, "Computation of new interaction indices for Indian Multiinfeed HVDC system using RTDS,” em CCEE, India, 2011.

[19] D. Khare, "RTDS Simulation Studies on the upcoming Multi-infeed HVDC Systems in India," em CPRI, Bangalore, India, 2008.

[20] R. Nayak, "AC/DC interactions in multi-infeed HVDC scheme: a case study," em Power India Conference, India, 2006.

[21] D. Lee Hau Aik e Goran Andersson, "VOLTAGE STABILITY ANALYSIS OF MULTI-INFEED HVDC SYSTEMS," IEEE Tiransactions on Power Delivery, vol. Vol. 12, n. No. 3, p. 10, July 1997.

[22] P. Fischer de Toledo, G. Asplund e E. Jansson, "Aspecs on infeed of multiple HVDC into one ac network," ABB Power System, HVDC Divsion, Sweden, p. 8.

[23] E. Rahimi, "Voltage interactions and commutation failure phenomena in multiinfeed HVDC systems, Ph. D. Thesis," University of Canada, Manitoba,Canada, 2011.

[24] F. R V de A Pedroso, S. G. D. Santo, M. T. Bassini, J. A. Jardini, J. F. Graham, G. Liu e Y. Wang, "Comparison of mitigation methods for commutation failure reduction on the Brazilian multi-infeed HVDC system," em Cigré Winnipeg 2017 Colloqiuum, Winnipeg, 2017.

[25] M. D. Simone, S. Gentili, G. Giannuzzi, F. Palone, M. Rebolini, R. Zaottini e S. Terna, "Commutation failures mitigation in multi-infeed network with high renewable penetration: Terna's experience,” B4-125, Cigré, Paris Session, p. 9, 2016. 
[26] M. A. B. Horita, F. R. V. de A. Pedroso, J. A. Jardini, J. F. Graham e L. Guijun, "HVDC multi-infeed analysis of the brazilian system," 2016 International High Voltage Direct Current Conference (HVDC 2016), p. 6, 2016.

[27] EPE, "Database for electromechanical transients," 0104 2016. [Online]. Available: http://www.epe.gov.br/Transmissao/Paginas/Basededadosparaestudosdetransit\%C3\%B 3rioseletromec\%C3\%A2nicos\%E2\%80\%93PDE2024.aspx?CategoriaID=. [Acesso em 1306 2016]. 


\section{ANNEX A}

Figure 20 - Commutation of valves 1 and 3.

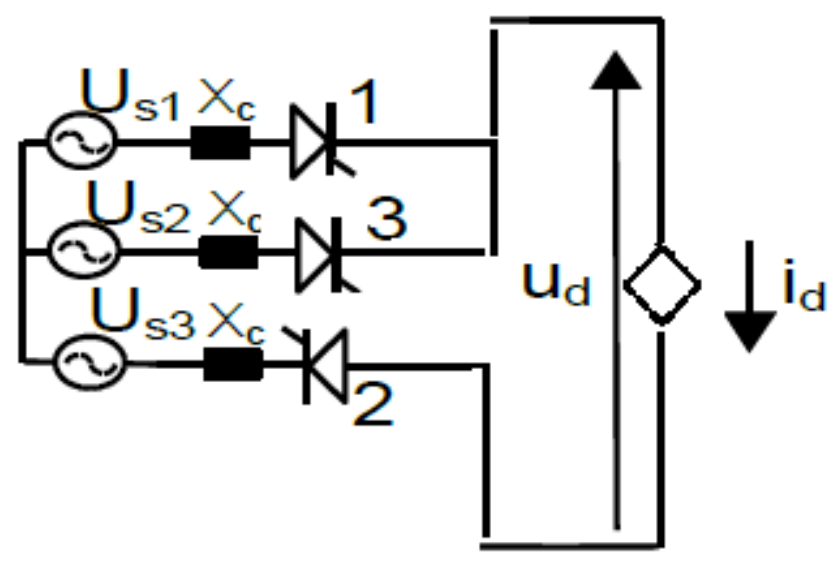

Source: Adapted from [4]

A short circuit can be seen between phases 1 and 2, with effects on the line AC voltage between the reactance and the valve and the current transmitted both AC and DC. As seen on Figure 21 at the moments where the voltage suddenly reaches zero value and on Figure 22 when current is transferred from valve 2 to valve 4 .

Figure 21 - Line voltage of AC grid.

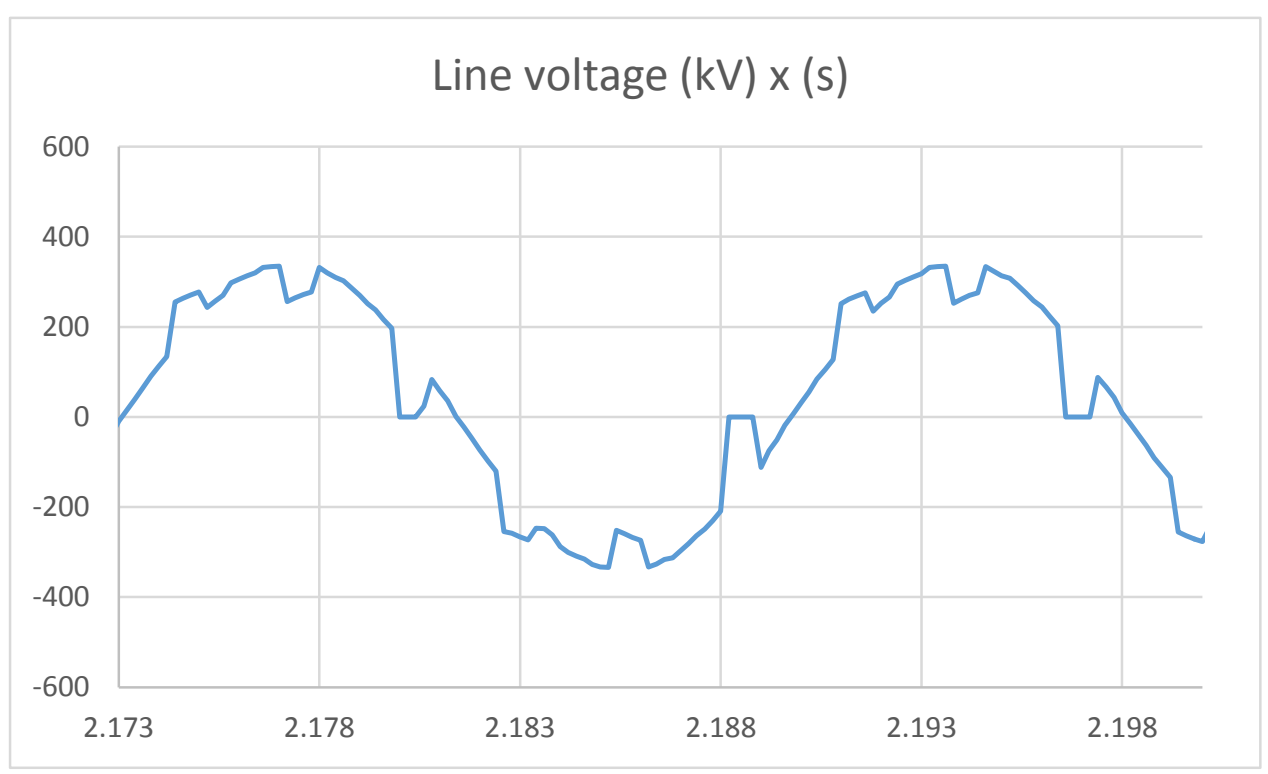

Source: Author 
Figure 22 - Current during a cycle focusing on the commutation process.

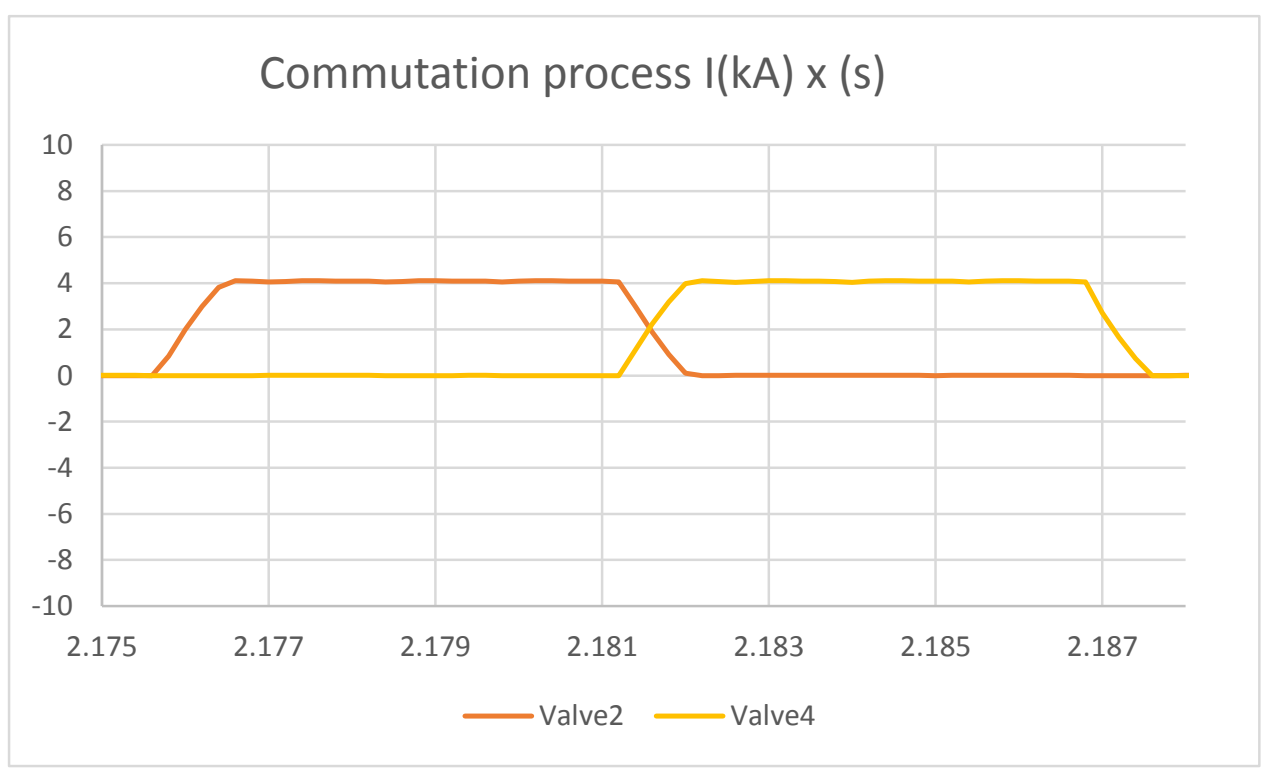

Source: Author

\section{ANNEX B}

Commutation failure happens when one valve fails to transfer its current to the subsequent valve and keeps conducting during a period longer than the correct operation period.

Figure 23 - Current during commutation failure.

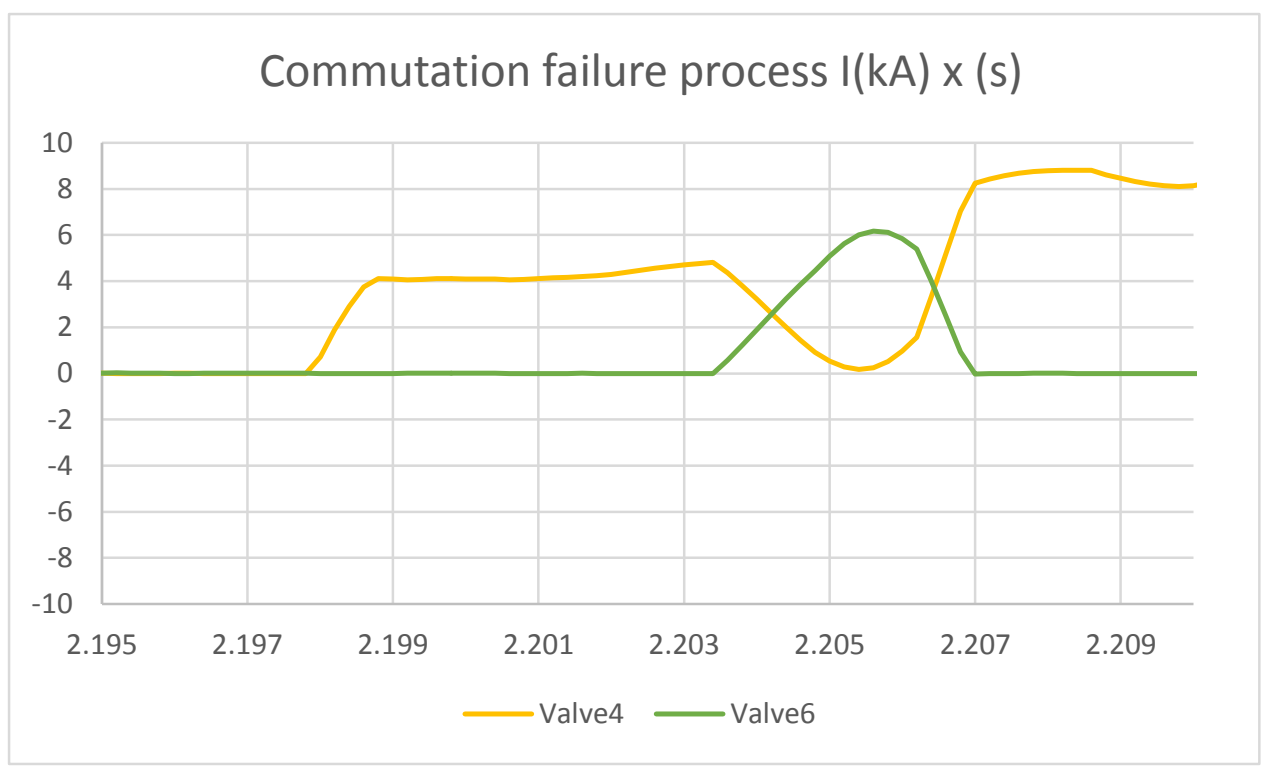

Source: Author 


\section{ANNEX C}

According to [16], the ESCR (Effective Short Circuit Ratio) is a parameter used to determine whether or not an AC system in which an HVDC system is operating is sufficiently strong to support its operation.

The ESCR is defined by:

$$
E S C R_{i}=\frac{S C C_{i}-Q f_{i}}{P d c_{i}}
$$

Where:

SCC - Short Circuit level

Qf - Shunt compensation of inverter bus

Pdc - HVDC link rated power

According to [11]:

- $2<$ ESCR very weak AC system;

- $2 \leq \mathrm{ESCR} \leq 3$ weak AC system;

- $\quad \mathrm{ESCR}>3$ strong AC system;

\section{ANNEX D}

The extinction angle of a converter is especially important at the inverter side of an HVDC link, since the extinction angle in an inverter has to be low to guarantee power transmission in the link.

Figure 24 shows the voltage on a valve during a correct cycle of operation, where:

- $2.155 \mathrm{~s} \leq \mathrm{t} \leq 2.161-$ Valve is conducting

- $2.161<\mathrm{t} \leq 2.162-$ Extinction angle

- $2.162<\mathrm{t} \leq 2.1717$ - Valve blocking 
Figure 24 - Extinction angle marked on valve voltage.

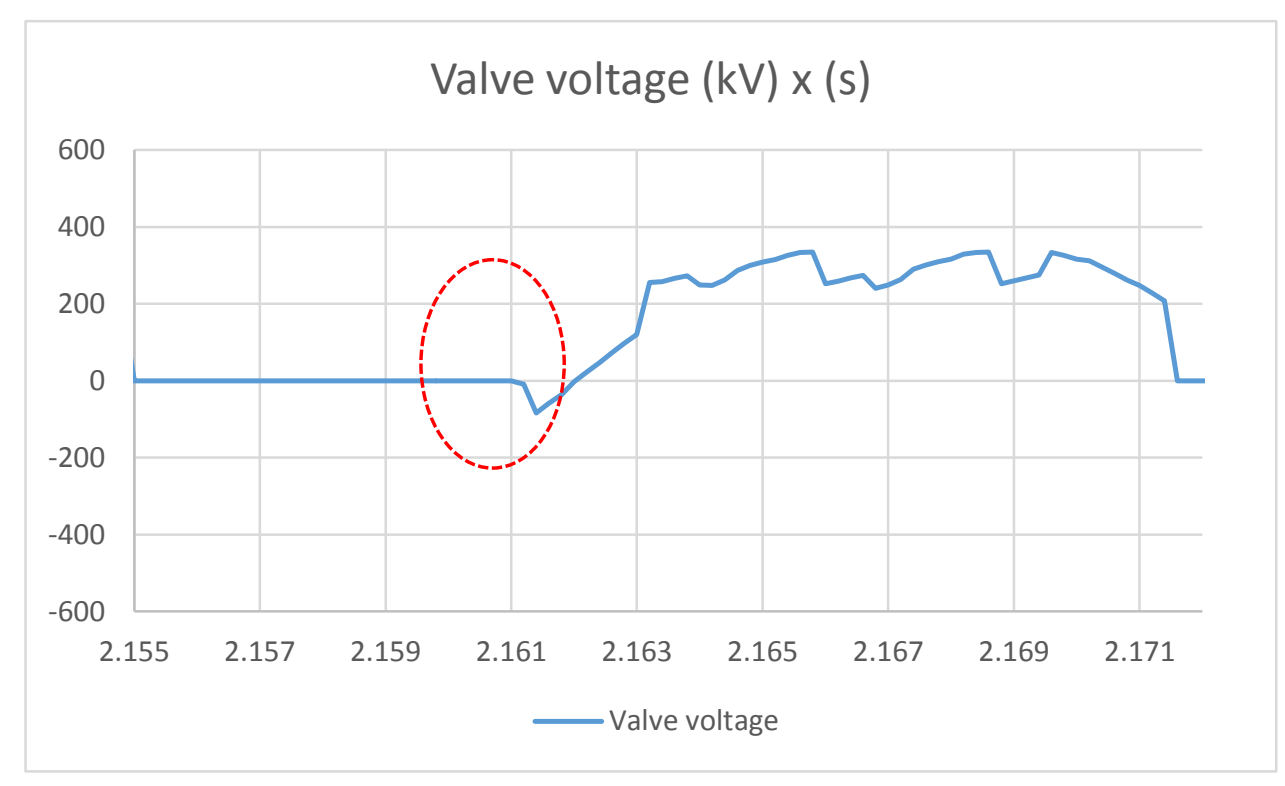

Source: Author

Disturbances of $\mathrm{AC}$ voltage are the most common reason of reduction of extinction angle under the minimum acceptable value $\left(\sim 8^{\circ}\right)$ [2]. Therefore, increasing the extinction angle provides the inverter a larger margin of deionization for consequent current blocking and enhances its capacity of withstanding commutation failure.

However, this mitigation has drawbacks, as follows [16]:

- Higher MVAr consumption;

- Higher valve stresses;

- Higher converter transformer rating;

- Higher costs;

\section{ANNEX E}

The ESCR was obtained through the short circuit software ANAFAS and it was used the EPE file for the year 2020. There are two ANAFAS files released by EPE for the year 2020 containing two possible scenarios, the Minimum Short-Circuit Scenario and the Maximum Short-Circuit Scenario. The ESCR was calculated for all 6 possible Load Flow situations (North Dry/Wet Season - Light, Average and Heavy Load) using short-circuit values obtained 
with both scenarios (Minimum and Maximum short-circuit). The short-circuit values obtained with ANAFAS is presented next.

Table 10 - Maximum Short-Circuit values for the year 2020 - ANAFAS EPE 2020

MAXIMUM SHORT CIRCUIT - 2020

\begin{tabular}{c|c|c|c|c|c|c|c}
\hline \multicolumn{2}{c|}{ BUS DATA } & \multicolumn{2}{c|}{ THREE-PHASE } & \multicolumn{2}{c|}{$\begin{array}{c}\text { PHASE-TO- } \\
\text { GROUND }\end{array}$} & \multicolumn{2}{c}{ TWO-PHASE } \\
\hline NUM. & NAME & MOD(kA) & ANG(gr) & MOD(kA) & ANG(gr) & MOD(kA) & ANG(gr) \\
\hline 3691 & IBIUNA-SP345 & 43.4 & -87 & 38.7 & -86.3 & 41.8 & 158.4 \\
\hline 4291 & TRIODC-RJ500 & 33.5 & -87.3 & 26.1 & -83.3 & 32 & 163.4 \\
\hline 4302 & ESTREI-MG500 & 33.4 & -86.8 & 23.1 & -83.1 & 31.1 & 166.8 \\
\hline 5202 & ARARA2-SP500 & 34.9 & -87 & 27.6 & -85.4 & 32.8 & 162.7 \\
\hline
\end{tabular}

Source: Author

Table 11 - Minimum Short-Circuit values for the year 2020 - ANAFAS EPE 2020

MINIMUM SHORT CIRCUIT - 2020

\begin{tabular}{c|c|c|c|c|c|c|c}
\hline \multicolumn{2}{c|}{ BUS DATA } & \multicolumn{2}{c|}{ THREE-PHASE } & \multicolumn{2}{c}{ PHASE-TO-GROUND } & \multicolumn{2}{c}{ TWO-PHASE } \\
\hline NUM. & NAME & MOD(kA) & ANG(gr) & MOD(kA) & ANG(gr) & MOD(kA) & ANG(gr) \\
\hline 3691 & IBIUNA-SP345 & 37.4 & -87.3 & 36.5 & -86.7 & 37.2 & 154.1 \\
\hline 4291 & TRIODC-RJ500 & 24.6 & -87.3 & 21.2 & -84.2 & 24 & 160.1 \\
\hline 4302 & ESTREI-MG500 & 25.4 & -86.7 & 18.1 & -82.3 & 23.9 & 166.4 \\
\hline 5202 & ARARA2-SP500 & 27.8 & -87.3 & 24.4 & -86 & 26.8 & 158.8 \\
\hline
\end{tabular}

Source: Author

In the last two tables, it was presented the current values for three-phase, two-phase and phase-to-ground short-circuits.

For the calculation of the ESCR it is used the three-phase short-circuit values along with the nominal power capacity of the converters/HVDC Systems and the total Reactive Power of the filters and capacitor banks installed/active in the converters buses. These information are presented below.

Table 12 - Nominal Power of the HVDC Systems planned to be operational by the year 2020.

\begin{tabular}{l|c|c}
\multicolumn{3}{l}{ HVDC SYSTEM INFORMATION } \\
\hline NAME & N Bipoles & Nominal Power (MVA) \\
\hline ITAIPU & 2 & 6300 \\
\hline
\end{tabular}




\begin{tabular}{l|l|l} 
BELO MONTE 1 & 1 & 4000 \\
\hline BELO MONTE 2 & 1 & 4000 \\
\hline RIO MADEIRA & 2 & 6300 \\
\hline
\end{tabular}

Source: Author

Table 13 - HVDC Filters Injected Reactive Power for the various Load Flow Situations.

HVDC Filters Total Reactive Power (Mvar)

\begin{tabular}{r|c|c|c|c|c|c}
\hline \#BUS & $\mathrm{LL}-\mathrm{ND}$ & $\mathrm{LL}-\mathrm{NW}$ & $\mathrm{AL}-\mathrm{ND}$ & $\mathrm{AL}-\mathrm{NW}$ & $\mathrm{HL}-\mathrm{ND}$ & $\mathrm{HL}-\mathrm{NW}$ \\
\hline $\mathrm{IB}$ & 2,415 & 1,252 & 3,502 & 3,514 & 3,459 & 3,431 \\
\hline $\mathrm{TR}$ & 453 & 885 & 919 & 2,391 & 457 & 2,303 \\
\hline $\mathrm{ES}$ & 471 & 2,376 & 449 & 2,356 & 432 & 1,824 \\
\hline $\mathrm{AR}$ & 1,394 & 3,911 & 3,978 & 4,736 & 2,803 & 4,343 \\
\hline
\end{tabular}

Source: Author

The total reactive power injected by the HVDC filters in the various Load Flow scenarios had to be calculated also. In the table's first line LL, AL, HL, ND and NW are short for Light Load, Average Load, Heavy Load, North Dry and North Wet respectively.

The next table shown below, presents the ESCR calculated for all Load Flow scenarios, using the maximum and minimum short circuit values.

Table 14 - ESCR Calculated with maximum and minimum short circuit values. a) Maximum short-circuit scenario; b) Minimum short-circuit scenario

a)

ESCR - MAXIMUM SHORT CIRCUIT

\begin{tabular}{r|c|c|c|c|c|c}
\hline \#BUS & $\begin{array}{c}\mathrm{LL}- \\
\mathrm{ND}\end{array}$ & $\begin{array}{c}\mathrm{LL}- \\
\mathrm{NW}\end{array}$ & $\mathrm{AL}-\mathrm{ND}$ & $\mathrm{AL}-\mathrm{NW}$ & $\mathrm{HL}-\mathrm{ND}$ & $\mathrm{HL}-\mathrm{NW}$ \\
\hline $\mathrm{IB}$ & 3.7 & 3.9 & 3.6 & 3.6 & 3.6 & 3.6 \\
\hline $\mathrm{TR}$ & 7.1 & 7 & 7 & 6.7 & 7.1 & 6.7 \\
\hline $\mathrm{ES}$ & 7.1 & 6.6 & 7.1 & 6.7 & 7.1 & 6.8 \\
\hline $\mathrm{AR}$ & 4.6 & 4.2 & 4.2 & 4 & 4.4 & 4.1 \\
\hline
\end{tabular}

Source: Author

b) 


\begin{tabular}{r|c|c|c|c|c|c}
\multicolumn{7}{c}{ ESCR - MINIMUM SHOR CIRCUIT } \\
\hline \#BUS & $\begin{array}{c}\mathrm{LL}- \\
\text { ND }\end{array}$ & $\begin{array}{c}\mathrm{LL}- \\
\mathrm{NW}\end{array}$ & AL $-\mathrm{ND}$ & $\mathrm{AL}-\mathrm{NW}$ & $\mathrm{HL}-\mathrm{ND}$ & $\mathrm{HL}-\mathrm{NW}$ \\
\hline $\mathrm{IB}$ & 3.2 & 3.3 & 3 & 3 & 3 & 3 \\
\hline $\mathrm{TR}$ & 5.2 & 5.1 & 5.1 & 4.7 & 5.2 & 4.8 \\
\hline $\mathrm{ES}$ & 5.4 & 4.9 & 5.4 & 4.9 & 5.4 & 5 \\
\hline AR & 3.6 & 3.2 & 3.2 & 3.1 & 3.4 & 3.1 \\
\hline
\end{tabular}

Source: Author

\section{ANNEX F}

A consequential commutation failure will drastically reduce the power transmitted by the HVDC links as shown below, both with synchronous generators and equivalent sources, as mentioned in section 5.3.2. That is the critical situation mentioned during the study that can cause massive load rejection and big outages.

Figure 25 - Power on Madeira bipoles

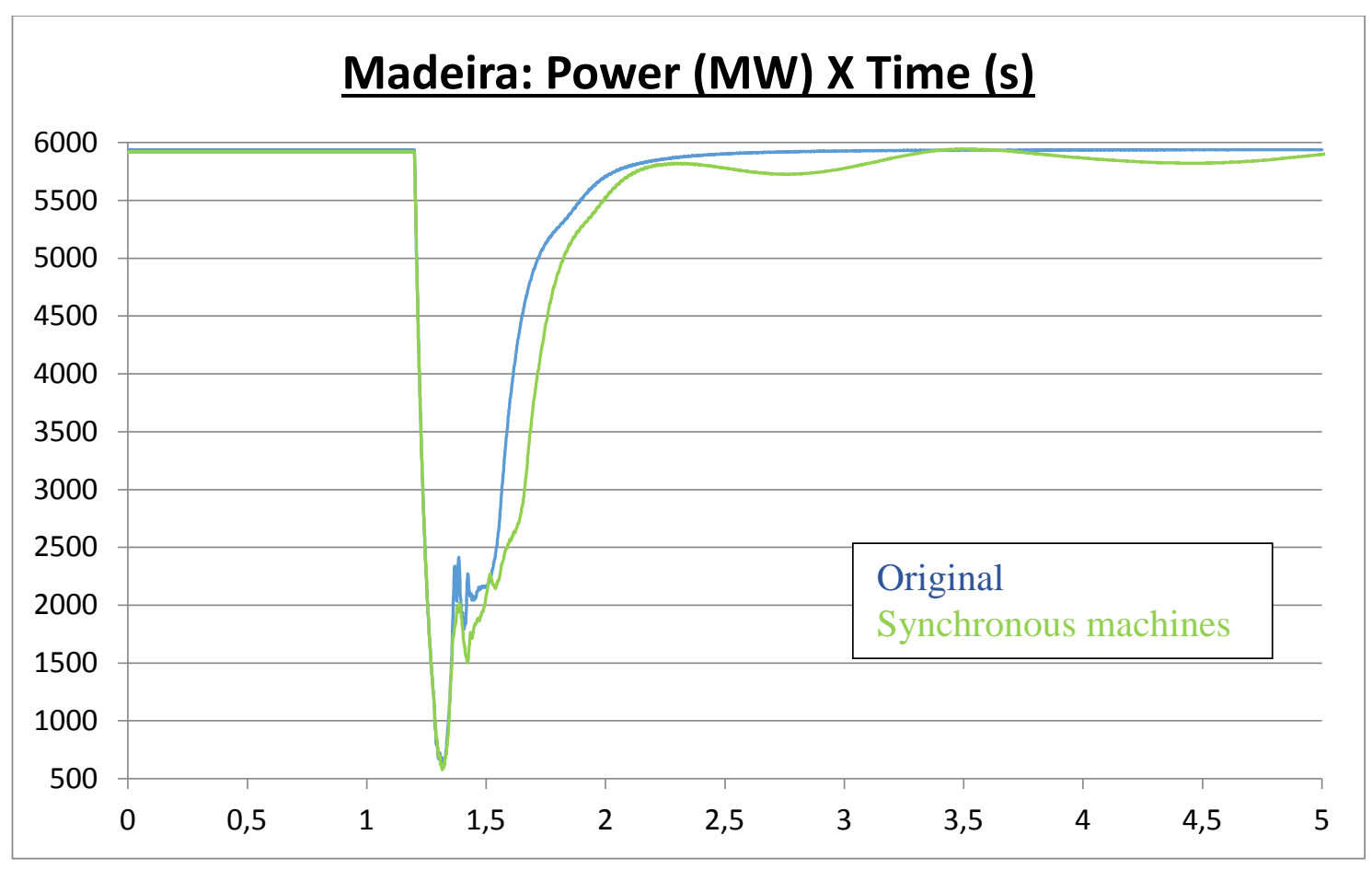

Source: Author 
Figure 26 - Power on Itaipu bipoles

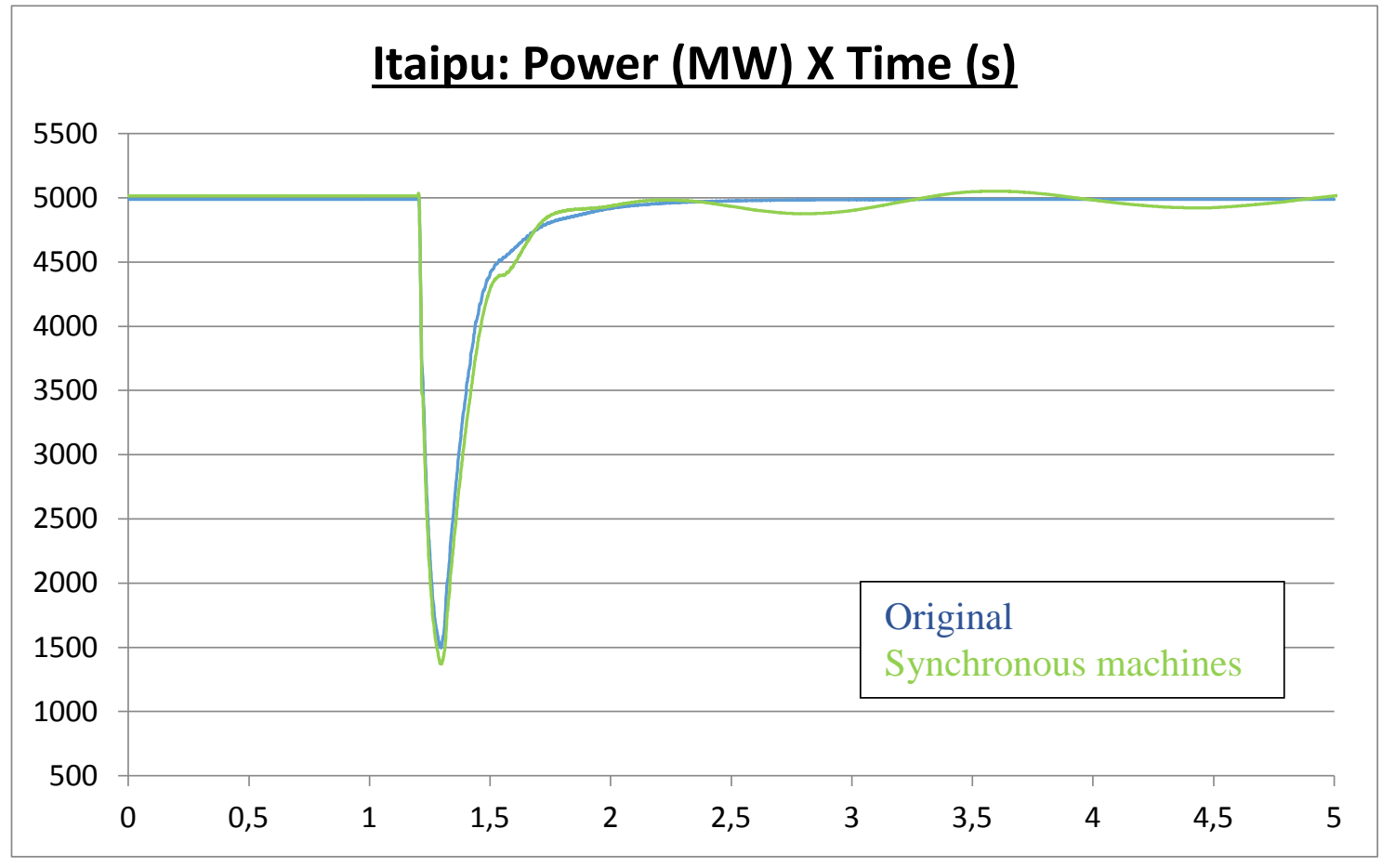

Source: Author

Figure 27 - Power on Belo Monte bipole 1 (Same figure presented in section 5.3.2 Power dispatched on the HVDC links).

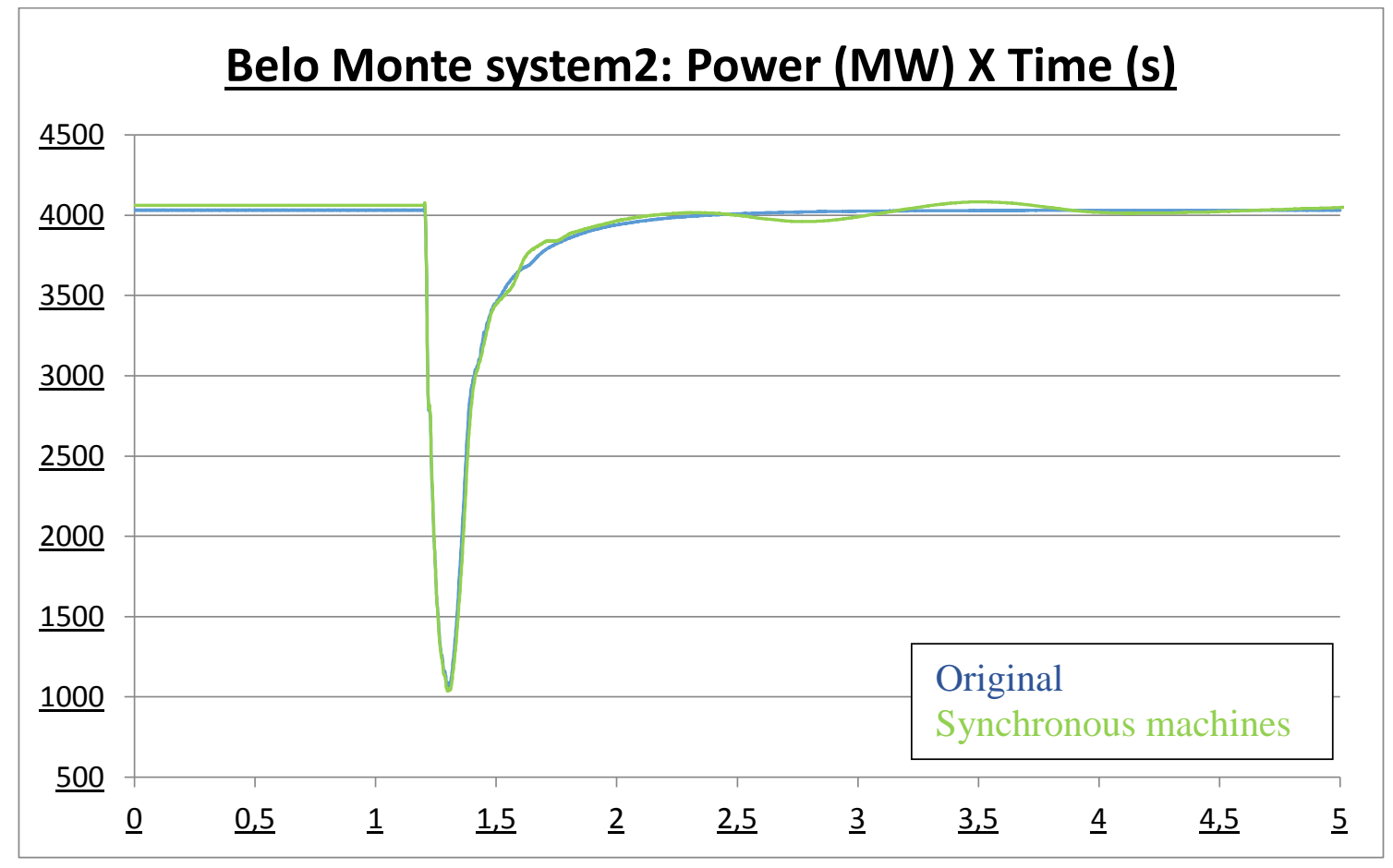

Source: Author 
Figure 28 - Power on Belo Monte bipole 2

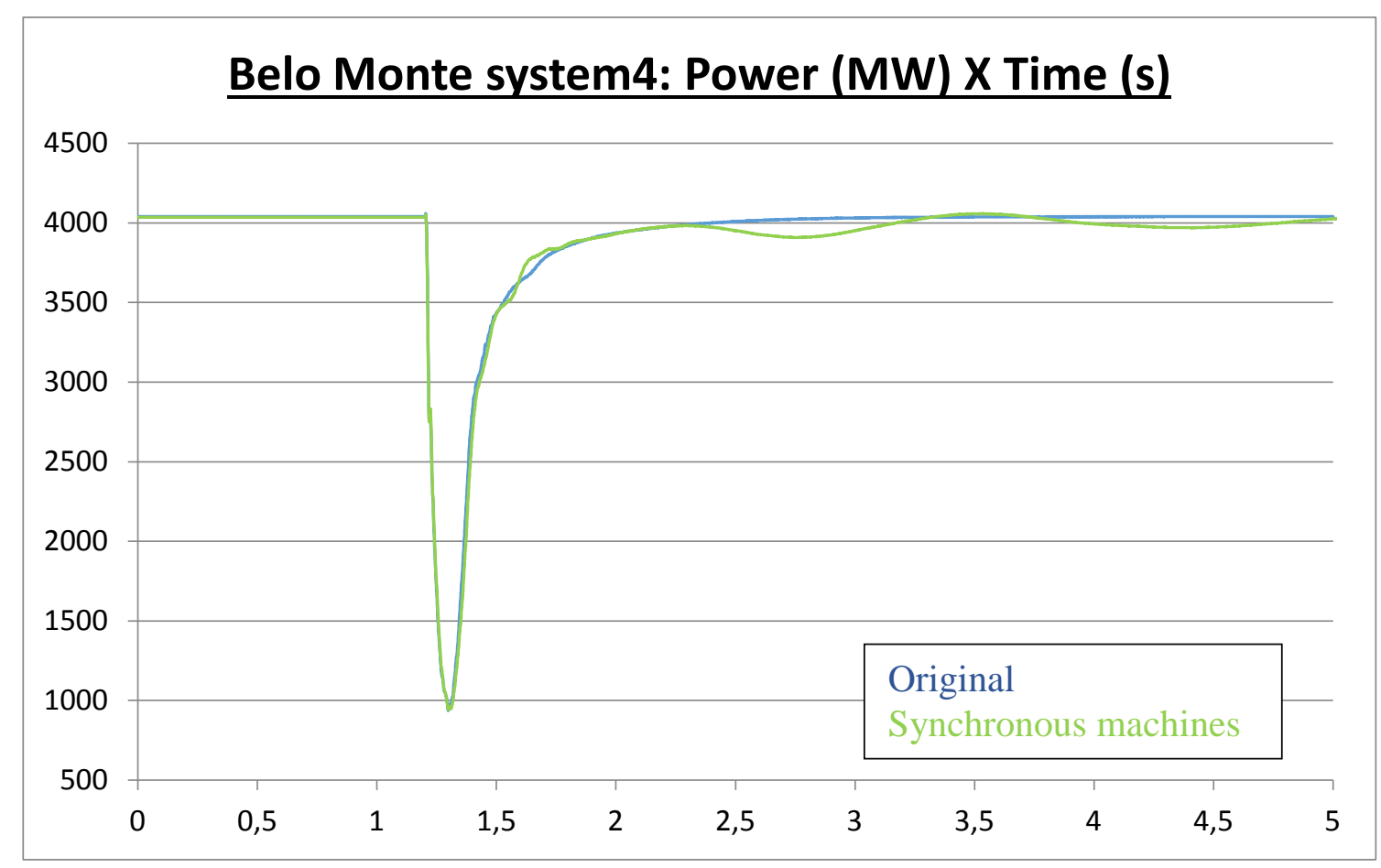

Source: Author

\section{ANNEX G}

The data used for synchronous machines parameters can be found at [27].

The synchronous machines were connected at points previously defined by EPE in the PSCAD multi-infeed system already mentioned. For the connection, a few transmission lines were included in the PSCAD model to represent the lines that physically connect the synchronous machines to the access points of the PSCAD model. Table 15 shows these lines. 
Table 15 - Lines included for the connection of the synchronous machines

\begin{tabular}{|c|c|c|c|c|c|c|}
\hline $\begin{array}{l}\text { Synchronous } \\
\text { generator }\end{array}$ & Emborcação & Furnas & Ilha Solteira & Itaipu & Porto Primavera & Xingó \\
\hline $\begin{array}{l}\text { Bus connection to } \\
\text { the synchronous } \\
\text { machine }\end{array}$ & EMBORCUHE013(1426) & FURNASUHE013(3587) & I.SOLTUHE014(2041) & ITAIPUUHE013(3584) & P.PRIMUHE013(2045) & XINGO1UHE013(89) \\
\hline $1^{\circ}$ line & $\begin{array}{c}\text { EMBORCUHE013(1426)- } \\
\text { EMBORC(1509) }\end{array}$ & $\begin{array}{l}\text { FURNASUHE013(3587)- } \\
\text { FURNAS(3808) }\end{array}$ & $\begin{array}{l}\text { I.SOLTUHE014(2041)- } \\
\text { I.SOLT(2611) }\end{array}$ & $\begin{array}{l}\text { ITAIPUUHE013(3584)- } \\
\text { ITAIPU(3641) }\end{array}$ & $\begin{array}{l}\text { P.PRIMUHE013(2045) } \\
\text {-P.PRIM(2074) }\end{array}$ & $\begin{array}{l}\text { XINGO1UHE013(89) } \\
\text {-XINGO(504) }\end{array}$ \\
\hline $2^{\circ}$ line & $\begin{array}{l}\text { EMBORC(1509)- } \\
\text { ITUMBI(3860) }\end{array}$ & $\begin{array}{l}\text { FURNAS(3808)- } \\
\text { ESTREI(3946) }\end{array}$ & $\begin{array}{l}\text { I.SOLT(2611)- } \\
\text { MIRAS2(2670) }\end{array}$ & $\begin{array}{l}\text { ITAIPU(3641)- } \\
\text { FOZ.IG(3633) }\end{array}$ & $\begin{array}{l}\text { P.PRIM(2074)- } \\
\text { TAQUAR(2620) }\end{array}$ & $\begin{array}{l}\text { XINGO(504)- } \\
\text { PAF4(500) }\end{array}$ \\
\hline $3^{\circ}$ line & $\begin{array}{l}\text { ITUMBI(3860)- } \\
\text { MARIMB(3853) }\end{array}$ & - & $\begin{array}{l}\text { MIRAS2(2670)- } \\
\text { ARARAQ(2630) }\end{array}$ & $\begin{array}{l}\text { FOZ.IG(3633)- } \\
\text { FOZ.IG(3642) }\end{array}$ & $\begin{array}{l}\text { TAQUAR(2620)- } \\
\text { ASSIS(2624) }\end{array}$ & $\begin{array}{l}\text { PAF4(500)- } \\
\text { OLINDI(582) }\end{array}$ \\
\hline $4^{\circ}$ line & $\begin{array}{l}\text { MARIMB(3853)- } \\
\text { MARIM2(4598) }\end{array}$ & - & $\begin{array}{l}\text { ARARAQ(2630)- } \\
\text { ARARA2(5203) }\end{array}$ & $\begin{array}{c}\text { FOZ.IG(3642)- } \\
\text { IV/FO(3651/3652/365 } \\
\text { 3) }\end{array}$ & $\begin{array}{l}\text { ASSIS(2624)- } \\
\text { BAURU(2628) }\end{array}$ & $\begin{array}{l}\text { OLINDI(582)- } \\
\text { CAMACA(574) }\end{array}$ \\
\hline $5^{\circ}$ line & - & - & $\begin{array}{l}\text { ARARA2(5203)- } \\
\text { ARARA2(5202) }\end{array}$ & $\begin{array}{l}\text { IV/FO(3651/3652/365 } \\
\text { 3)-IVAIPO(3654) }\end{array}$ & $\begin{array}{l}\text { BAURU(2628)- } \\
\text { CABREU(2647) }\end{array}$ & $\begin{array}{l}\text { CAMACA(574)- } \\
\text { SAPEAC(589) }\end{array}$ \\
\hline $6^{\circ}$ line & - & - & - & $\begin{array}{c}\text { IVAIPO(3654)- } \\
\text { IV/IT(3661/3662/366 } \\
\text { 3) }\end{array}$ & $\begin{array}{l}\text { CABREU(2647)- } \\
\text { F.DIAS(4321) }\end{array}$ & $\begin{array}{l}\text { SAPEAC(589)- } \\
\text { IBICOA(588) }\end{array}$ \\
\hline $7^{\circ}$ line & - & - & - & $\begin{array}{c}\text { IV/IT(3661/3662/366 } \\
\text { 3)-ITABER(3664) }\end{array}$ & - & $\begin{array}{l}\text { IBICOA(588)- } \\
\text { IGAPO3(11594) }\end{array}$ \\
\hline
\end{tabular}




\begin{tabular}{c|c|c|c|c|c}
\hline $\begin{array}{c}\text { Synchronous } \\
\text { generator }\end{array}$ & Emborcação & Furnas & Ilha Solteira & Itaipu & Porto Primavera \\
\hline $8^{\circ}$ line & - & - & - & $\begin{array}{c}\text { ITABER(3664)- } \\
\text { IT/TP3(3665/3666/36 } \\
67)\end{array}$ & $\begin{array}{c}\text { Xingó } \\
\text { IGAPO3(11594)- } \\
\text { JANAU3(38900) }\end{array}$ \\
\hline $9^{\circ}$ line & - & - & - & $\begin{array}{c}\text { IT/TP3(3665/3666/36 } \\
67) \text { T.PRET(3668) }\end{array}$ & $\begin{array}{c}\text { JANAU3(38900)- } \\
\text { JUSCEL(26465) }\end{array}$ \\
\hline $10^{\circ}$ line & - & - & - & - & JUSCEL(26465)- \\
ITABI5(26510)
\end{tabular}

Source: Author

Where:

The number between parenthesis is the number of the bus in the ANAREDE model found in [5]. 